\title{
Corrosion Resistance and Microstructure of Welded Duplex Stainless Steel Surface Layers on Gray Cast Iron
}

\author{
B. Heider ${ }^{1} \cdot$ M. Oechsner ${ }^{1} \cdot$ U. Reisgen ${ }^{2} \cdot$ J. Ellermeier ${ }^{1}$. T. Engler ${ }^{1}$ \\ G. Andersohn ${ }^{3} \cdot$ R. Sharma ${ }^{2}$ E. Gonzalez Olivares ${ }^{2} \cdot$ E. Zokoll ${ }^{2}$
}

Submitted: 11 November 2019/in revised form: 11 February 2020/Published online: 3 March 2020

(C) The Author(s) 2020

\begin{abstract}
The degradation of pump components by corrosion and complex, simultaneous damage mechanisms, e.g., erosion-corrosion and cavitation-corrosion leads to high costs through replacement and maintenance of parts. To increase the lifetime of cost-efficient components with superior casting properties, surface welding of duplex stainless steel on gray cast iron parts was performed using inert shielding gas metal arc surface welding (GMA-SW) and plasma transferred arc surface welding (PTA-SW). The thermal conductivity of the used shielding gas and the preheating temperature influenced the dilution of the surface layers, which had a major impact on the corrosion resistance and the microstructure. Lower cooling rates enhanced diffusion and lead to precipitation of carbides. High heat input and prolonged cooling times during surface welding resulted in high dilution and a carbide network. The corrosion resistance in artificial seawater of those surface layers was substantially reduced compared to surface layers with lower heat input and higher cooling rates.
\end{abstract}

This article is an invited paper selected from presentations at the 2018 International Thermal Spray Conference, held May 7-10, 2018, in Orlando, Florida, USA, that has been expanded from the original presentation.

B. Heider

heider@mpa-ifw.tu-darmstadt.de

1 Technical University of Darmstadt, Mechanical Engineering, Center for Structural Materials, State Materials Testing Institute Darmstadt (MPA), Chair and Institute for Materials Technology (IfW), Grafenstraße 2, 64283 Darmstadt, Hessen, Germany

2 Welding and Joining Institute ISF, RWTH Aachen University, 52062 Aachen, Nordrhein-Westfalen, Germany

3 AHC Oberflächentechnik GmbH, Boelckestraße 25-57, 50171 Kerpen, Nordrhein-Westfalen, Germany
The corrosion of the surface layers in the potentiodynamic polarization test was driven by selective corrosion of the phase boundary between $\mathrm{Cr}$-carbides and $\mathrm{Cr}$-depleted austenite. Passive behavior was observed for surface layers with low dilution, which had homogeneous chromium distribution and no carbide networks. In conclusion, the corrosion behavior of gray cast iron was improved by surface welding with duplex stainless steel. The corrosion resistance of the surface layers produced with PTA-SW with no preheating exceeded that of the surface layers produced with GMA-SW and came close to those of a commercially available duplex stainless steel used as reference material.

Keywords dilution - duplex stainless steel · electrochemical corrosion - gas metal arc welding - gray cast iron $\cdot$ microstructure $\cdot$ plasma transferred arc welding

\section{Abbreviations \\ GMA-SW Gas metal arc surface welding \\ PTA-SW Plasma transferred arc surface welding \\ SEM Scanning electron microscope \\ EDX Energy-dispersive $\mathrm{x}$-ray spectroscopy \\ EIS Electrochemical impedance spectroscopy \\ CPE Constant phase element}

\section{List of Symbols \\ $X_{\mathrm{i}} \quad$ Concentration of element $\mathrm{X}$ in the surface layer \\ $X_{\mathrm{B}} \quad$ Concentration of element $\mathrm{X}$ in the base metal \\ $X_{\mathrm{W}}$ Concentration of element $\mathrm{X}$ in the consumable \\ $R_{\mathrm{S}} \quad$ Solution resistance \\ $R_{\mathrm{ct}} \quad$ Charge transfer resistance \\ $C_{\mathrm{dl}} \quad$ Double-layer capacitance}




\section{Introduction}

Pump components used in maritime, offshore as well as in the chemical industry are subjected to rough conditions caused by corrosive media and abrasive particles (Ref 1,2). To prevent erosion and cavitation damage, the flow conditions are optimized through the geometry of such parts, which often results in complex shapes (Ref 3). Therefore, casting represents a suitable manufacturing process. Lamellar gray cast iron is used for pump components due to its advantageous casting and damping characteristics, but the corrosion resistance is poor (Ref 4$)$. More durable and more expensive materials are necessary to increase the lifetime of such parts (Ref 5). Duplex stainless steels represent a material class that is highly resistant to corrosion in aqueous, saline media and in various aggressive chemicals (Ref 6). The superior properties of those steels are achieved by careful manufacturing and precise heat processing, which is very difficult for geometrically complex cast components. Consequently, coating of cast parts with duplex stainless steel is a reasonable approach. Among coating processes, e.g., physical and chemical vapor deposition, galvanizing, thermal spraying, etc., surface welding yields a tough, metallurgical bonding (Ref 7-10). Duplex stainless steels and gray cast irons both require very different heat treatments, which is a challenge for successful surface welding: On the one hand, fast cooling rates after welding of lamellar gray cast iron cause embrittlement and cracking due to martensite formation. On the other hand, too slow cooling rates of duplex stainless steel lead to embrittlement by precipitation of, e.g., carbides, $\sigma$-phase and $\alpha^{\prime}$-phase $\left(475{ }^{\circ} \mathrm{C}\right.$ embrittlement) (Ref 11-13).

Successful surface welding of duplex stainless steel on lamellar gray cast iron comprises a crack-free surface layer with superior corrosion properties to gray cast iron. The most promising approach is to aim for a low dilution with a bargain cooling rate. Gas metal arc surface welding (GMA$\mathrm{SW}$ ), especially the cold metal transfer process (CMT), and plasma transferred arc surface welding (PTA-SW) have been used to produce such surface layers (Ref 14). The influences of surface welding parameters, e.g., helium content in the shielding gas and preheating temperature, on the weld beads were discussed in detail (Ref 15, 16). This paper investigates the chemical compositions and microstructures of the surface layers and discusses the differences that originate from variations of surface welding parameters. The corrosion properties are tested with electrochemical methods, and the corrosion mechanisms are investigated by electron probe analyses.

\section{Surface Welding of Duplex Stainless Steel on Lamellar Gray Cast Iron}

During welding, the surface of a base metal is molten and consumable is added to form a liquid pool where the two materials fuse and a metallurgical bond is created upon solidification. The cooling rates in welding are very high due to heat conduction in the base metal, so the solidification happens very fast and far from equilibrium conditions. Depending on the exact cooling rates, solid phase transformations take place.

Welding implies mixing of the consumable and the base metal which leads to alterations of the composition, the microstructure and the properties of the resulting surface layer as compared to the pure consumable. The ratio of the actual composition of a surface layer compared to the composition of the pure consumable and the base metal is termed dilution. It influences the microstructure, which vice versa influences the corrosion resistance as well (Ref 17). Both dilution and cooling rate are very important to the properties of the surface layer, especially in the case of a duplex stainless steel (Ref 18).

Adding helium to an argon shielding gas increases the thermal conductivity of the gas and thus results in (i) larger heat input and (ii) a wider heat-affected zone. Both lead to reduced cooling rates, as does preheating of the plate (Ref 15). Preheating also maintains the plate and the surface layer at elevated temperatures, thereby facilitating diffusion processes and phase transformations. As the surface layer is produced by placing one weld bead next to the other, the already solidified weld beads will partially melt again or at least experience some heat treatment. This also influences the resulting microstructure of the surface layers. Two different welding methods were used to prepare surface layers with varying dilutions: GMA-SW and PTASW. As their differences are already discussed in detail, only a short survey and the variations of parameters are given here (Ref 15).

\section{Gas Metal Arc Surface Welding}

In GMA-SW, a solid electrode is heated by an arc between the electrode itself and the base metal. The arc has an opening angle of approximately $45^{\circ}$, so an area of the base metal with 4-5 mm diameter around the center of the arc is heated as well, depending on the distance of the electrode tip to the base metal. As the electrode tip surpasses the melting temperature, droplets detach onto the surface of the base metal. During the short circuit between the electrode and the base metal, a high current flows between the two, and thus, a high heat input is induced. The cold metal transfer process is a digitally controlled welding process that minimizes the current and retracts the solid electrode 
during the shortcut to reduce the heat input and to facilitate droplet detachment (Ref 19, 20). The liquid pool is protected from oxidation and atmospheric contamination by a shielding gas. The thermal conductivity of the shielding gas also influences the shape of the arc, of the weld pool and the amount of heat input. The width of the weld pool and the heat input increase with higher heat conductivity of the shielding gas. Due to the higher heat conductivity compared to argon, welding with helium as a shielding gas produces a broader weld pool and increases the temperatures and the heat input on the base metal (Ref 21). A sort of restriction to the GMA-SW process is that the melting of the electrode and the stability of the arc are coupled, i.e., the welding parameters cannot be adjusted arbitrarily. This stands opposed to the aim of a minimum heat input on the base material and a minimum dilution of consumable and base metal in the surface layer.

\section{Plasma Transferred Arc Welding}

In PTA-SW, a pilot arc between the plasma gas nozzle and a tungsten electrode is used to ignite the inflowing plasma gas. The plasma arc can be considered as almost cylindrical with a homogeneous energy distribution. The diameter is determined by the diameter of the plasma gas nozzle which is typically a few millimeters. The consumable in form of a powder is transported with a feeding gas through a second nozzle, the powder nozzle, into the plasma arc where it melts and drops onto the base metal to form the weld pool. Shielding gas from a third nozzle protects the liquid weld pool from oxidation and atmospheric contamination. An advantage over GMA-SW is that in PTA-SW the powder feeding rate, that is analogous to the electrode melting rate, and the energy provided by the arc can be adjusted separately. Through this, the heat input may be adjusted to a minimum, so that only a very thin layer on surface of the base metal is molten and fused with the consumable to a surface layer with very low dilution.

\section{Properties of Duplex Stainless Steel Surface Layers}

The applied consumables have a composition similar to steel grade $\mathrm{X} 2 \mathrm{CrNiMoN} 22-5-3$ (1.4462), whose microstructure, after ideal heat treatment by solution annealing and quenching, consists of about $40-60 \%$ ferrite with balance austenite. This composition offers sufficient hardness as well as ductility and an excellent corrosion resistance due to about $23 \%$ chromium content (Ref 12). A minimum amount of $11 \%$ chromium is recommended to enable surface passivation in moderate corrosive environments by formation of a chromium oxide layer (Ref 22). High levels of dilution with gray cast iron might eventually reduce the chromium content of the surface layer below
$11 \%$. However, as this can only be the case for high levels of dilution $(>50 \%)$, other factors are more important to a sufficient corrosion resistance of the produced surface layers:

- The formation and precipitation of phases upon cooling: Phases that need to be considered are retained $\delta$ ferrite, $\sigma$-phase and especially carbide phases (Ref 13). The latter are of importance because chromium has a high affinity to bond with carbon. This depletes the phase boundaries of chromium and renders them susceptible to corrosion (Ref 23).

- Prolonged diffusion times that may facilitate the formation of carbide phases: The diffusion times are increased by preheating, which lowers the cooling rates, keeps the substrate and surface layer at high temperature and therefore reduces residual stresses and the risk of cracking (Ref 24). Cracks in the surface layer represent failure of the corrosion protection.

- The width of the heat-affected zone surface: Helium increases the heat conductivity of the shielding gas, thereby increasing the width of the heat-affected zone, while the shape of the arc also determines the surface area that is heated, i.e., the area of enhanced diffusion (Ref 21, 25).

- The welding speed and the deposition rate determine the time required to cover a given area of the base metal by surface welding. Low welding speeds imply long durations during which heat is added to the base metal and already solidified surface layer. This is also a factor that may enhance diffusion and precipitation processes. The deposition rate in GMA-SW is high, but the plasma transferred arc process can be optimized to achieve comparable deposition rates, however, at lower welding speeds.

These four factors have a high impact on the composition and the resulting microstructure of the surface layer. This paper presents the results of detailed microstructural and composition analyses and their effect on the corrosion mechanisms of the surface layers.

\section{Methods}

\section{Gas Metal Arc Welding}

At first, bead-on-plate welds were deposited on gray cast iron (EN-GJL-250) plates with dimensions $(w \times l \times h) 200 \times 300 \times 8 \mathrm{~mm}$ to determine a set of fixed parameters that produce a weld bead with good superficial appearance and low dilution while maintaining a stable process. Using these parameters, surface layers were welded on an area of about $(w \times l) 100 \times 250 \mathrm{~mm}$. 
A solid wire electrode with $1 \mathrm{~mm}$ diameter supposed for welding of duplex stainless steel was used (Ref 26). For investigation of the influence of cooling rates and prolonged diffusion times, the preheating temperature was varied between $25^{\circ} \mathrm{C}$ (no preheating) and $400{ }^{\circ} \mathrm{C}$ and the amount of helium in the shielding gas was increased from a pure argon gas $(0 \% \mathrm{He})$ to a gas mixture with $30 \%$ helium (ArHe30) to pure helium $(100 \% \mathrm{He})$ to increase the heat conductivity of the shielding gas. The synergetic cold metal transfer adapts to the environmental conditions (preheating and shielding gas composition) and controls the welding current and voltage to maintain the stability of the arc (Table 1). Additionally, to obtain one sample with high purity, a five-pass overlay-welding was performed on a plate of low-alloy steel S355. This sample with approx. $0 \%$ dilution is termed all-weld metal and will serve as a reference to the (maximum) potential of surface welded duplex stainless steel.

\section{Plasma Transferred Arc Welding}

Analogous to the procedure followed with GMA-SW, a set of parameters that produce a weld bead with acceptable superficial appearance and low dilution was established for PTA-SW of duplex stainless steel on gray cast iron. The used consumable has a powder fraction of $-150+53 \mu \mathrm{m}$ (Ref 27). Different to GMA-SW, an oscillation of the torch with $20 \mathrm{~mm}$ amplitude and $1 \mathrm{~Hz}$ frequency was applied during the surface welding. The influence of cooling rates and prolonged diffusion times was investigated by variation of the preheating temperature to $25{ }^{\circ} \mathrm{C}$ (no preheating), $200{ }^{\circ} \mathrm{C}$ and $400{ }^{\circ} \mathrm{C}$. Argon was used as plasma gas, feeding gas and shielding gas. Through the separated arc control and powder feed, the adjusted welding current and voltage do not adapt to the environmental conditions (preheating temperature) and are kept constant instead (Table 2).

Table 1 Variation of parameters for gas metal arc surface welding (GMA-SW)

\begin{tabular}{lccl}
\hline Current, A & Voltage, V & Preheating temperature, ${ }^{\circ} \mathrm{C}$ & Shielding gas \\
\hline 102.0 & 12.9 & 25 & $\mathrm{Ar}$ \\
117.6 & 17.3 & 400 & $\mathrm{Ar}$ \\
122.0 & 19.1 & 25 & $\mathrm{ArHe} 30$ \\
154.6 & 23.1 & 400 & $\mathrm{ArHe} 30$ \\
114.5 & 23.8 & 25 & $\mathrm{He}$ \\
118.2 & 24.8 & 400 & $\mathrm{He}$ \\
\hline
\end{tabular}

Fixed parameters: arc length $=14 \mathrm{~mm}$, torch inclination $=20^{\circ}$, travel speed $=40 \mathrm{~cm} \mathrm{~min}{ }^{-1}$, shielding gas flow $=181 \mathrm{~min}^{-1}$, wire feeding rate $=7 \mathrm{~m} \mathrm{~min}^{-1}$, wire diameter $=1 \mathrm{~mm}$ and deposition rate $=2.6 \mathrm{~kg} \mathrm{~h}^{-1}$,

\section{Chemical and Microstructural Characterization}

To prevent any unaccounted heat input, water jet cutting is used to cut round specimens from the prepared plates for chemical and metallographic analyses and for corrosion tests. The neighboring weld beads that comprise the surface layer cause high surface roughness, so all specimens are smoothened by mechanical, water-cooled grinding (600 grit).

The chemical composition in weight percent is determined by spark optical emission spectroscopy at three spots on the surface layers. From the elemental concentration in the surface layer $X_{\mathrm{i}}$ of elements $\mathrm{Fe}, \mathrm{Cr}$ and $\mathrm{Ni}$, the corresponding concentration of the base material $X_{\mathrm{B}}$ and the consumable $X_{\mathrm{W}}$, the mean dilution is determined by Eq 1 (Ref 28, 29) (Fig. 1).

$\%$ Dilution $=\frac{X_{\mathrm{i}}-X_{\mathrm{W}}}{X_{\mathrm{B}}-X_{\mathrm{W}}} * 100 \%$.

On the cross section of the surface layers, energy-dispersive $\mathrm{x}$-ray spectroscopy (EDX) at single spots as well as concentration mappings of selected elements is applied to further assess the microstructure and to reconstruct the solidification mechanisms of the surface layers. It is noted,

Table 2 Variation of parameters for plasma transferred arc surface welding (PTA-SW)

\begin{tabular}{lcc}
\hline Current, A & Voltage, V & Preheating temperature, ${ }^{\circ} \mathrm{C}$ \\
\hline 149.1 & 19.5 & 25 \\
149.1 & 19.2 & 200 \\
149.2 & 19.2 & 400 \\
\hline
\end{tabular}

Fixed parameters: arc length $=5 \mathrm{~mm}$, plasma gas nozzle diameter $=3 \mathrm{~mm}$, torch inclination $=0^{\circ}$, travel speed $=5 \mathrm{~cm} \mathrm{~min}^{-1}$, oscillation amplitude $=20 \mathrm{~mm}$, oscillation frequency $=1 \mathrm{~Hz}$, plasma gas flow $=0.51 \mathrm{~min}^{-1}$, feeding gas flow $=31 \mathrm{~min}^{-1}$, shielding gas flow $=101 \mathrm{~min}^{-1}$ and deposition rate $=1.4 \mathrm{~kg} \mathrm{~h}^{-1}$

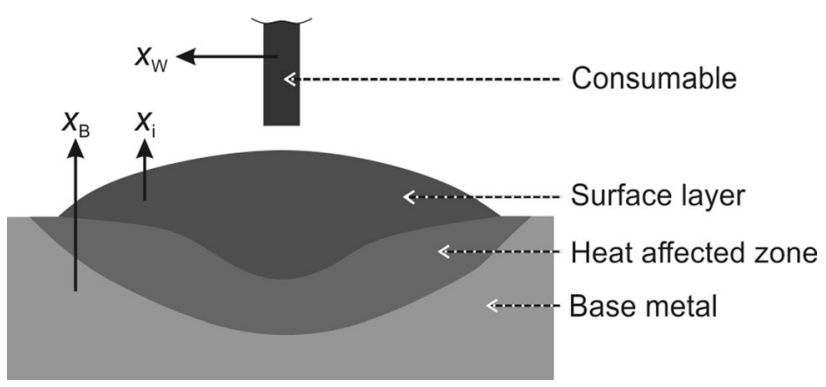

Fig. 1 Schematic drawing of a surface layer composed of a single weld bead prepared by gas metal arc welding. The composition of the surface layer is a mixture of consumable and base metal with the chemical compositions being: $X_{\mathrm{i}}$ : the surface layer, $X_{\mathrm{W}}$ : the consumable and $X_{\mathrm{B}}$ : the base metal 
that carbon cannot be quantified reliably by EDX, but the determined values are useful for comparison if the measurement conditions remain constant. Therefore, relative carbon concentrations are given and discussed only qualitatively.

\section{Corrosion Testing}

To investigate the corrosion resistance of the surface layers in an application-related environment, electrochemical tests are performed in artificial seawater prepared following DIN 50905-4:2017-07. A ring-shaped galvanic tape is applied on the surface to obtain a defined test surface area of $1 \mathrm{~cm}^{2}$

Potentiodynamic polarization tests are used to investigate the formation of a passive layer and corrosion kinetics under external polarization of the sample surface. The polarization range is $-200 \mathrm{mV}$ to $+1200 \mathrm{mV}$ versus open circuit potential (recorded for $900 \mathrm{~s}$ ), and the scanning speed is $1000 \mathrm{mV} / \mathrm{h}$. The form of the current densitypotential curve, the open circuit potential and the breakthrough potential are discussed to explain the kinetic behavior of active or passive corrosion.

Electrochemical impedance spectroscopy (EIS) is used to investigate the formation of (passive) layers that form without external polarization. The potential range is \pm $10 \mathrm{mV}$ versus open circuit potential, and the scanned frequency range is $100,000-0.02 \mathrm{~Hz}$. Impedance spectroscopy measurements are taken after $24 \mathrm{~h}$ recording of open circuit potential. Due to the nondestructive character of the EIS measurement, this is also considered as a 1-day immersion test. A modeling approach using a simplified Randles cell as equivalent circuit allows estimation of the double-layer capacitance, the charge transfer resistance and the solution resistance (Fig. 2). The capacity is replaced by a constant phase element (CPE), because it produces better fitting results. From a physical point of view, the constant phase element accounts for, e.g., surface roughness (Ref 30). The software Gamry Echem Analyst (Version 7.03, C3 Prozess-und Analysentechnik GmbH, Munich, Germany) is capable of constructing the equivalent circuit and modeling the data. It provides the values for the elements of the

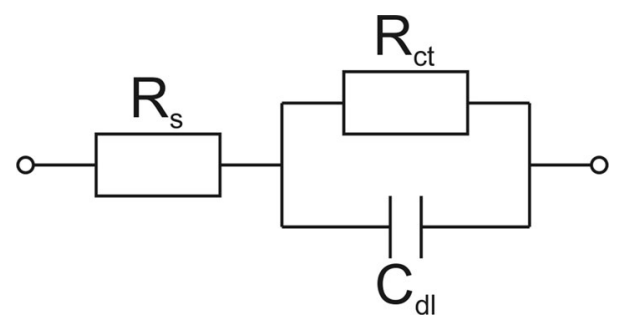

Fig. 2 Simplified Randles cell. $R_{\mathrm{s}}$ : solution resistance, $R_{\mathrm{ct}}$ : charge transfer resistance and $C_{\mathrm{dl}}$ : double-layer capacitance circuit and has all means to convert the values obtained for the CPE into a capacity.

Cross sections of the samples corroded in the potentiodynamic polarization measurements are prepared for metallographic investigation. Etching reveals selective corrosion mechanisms as well as the phase composition. EDX mappings and single spot analysis is an excellent means to visualize, e.g., chromium depletion.

\section{Results}

\section{Chemical and Microstructural Investigation}

The dilution increases with both preheating temperature and, for the surface layers produced with GMA-SW, increasing amount of helium in the shielding gas (Table 3). At highest dilution, the carbon concentration increases as high as $1.31 \%$, while the chromium concentration decreases as low as $13.3 \%$. The iron content increases and the nickel content decreases with increasing dilution. For PTASW without preheating, the dilution is only $2.02 \%$, i.e., the composition is nearly the same as that of the reference duplex stainless steel.

Using the formulas and the diagram developed by Schaeffler, the chromium and nickel equivalents predict a composition of approx. 50\% austenite and 50\% ferrite for the consumables. For decreasing percentages of chromium equivalent and increasing percentages of nickel equivalent, i.e., for increasing dilution, the Schaeffler diagram predicts increasing amounts of austenite (Ref 31). In the area of interest of the Schaeffler diagram, a higher chromium equivalent promotes ferrite formation, while a higher nickel equivalent promotes austenite formation. For a chromium equivalent (Eq 2) lower than $24 \%$ and a nickel equivalent (Eq 3) higher than 19\%, corresponding to a calculated dilution of $10 \%$, a microstructure of $100 \%$ austenite is to be expected.

$$
\begin{aligned}
& \% \mathrm{Ni}_{\text {eq }}=\% \mathrm{Ni}+30 \cdot \% \mathrm{C}+0.5 \cdot \% \mathrm{Mn} \\
& \% \mathrm{Cr}_{\text {eq }}=\% \mathrm{Cr}+\% \mathrm{Mo}+1.5 \cdot \% \mathrm{Si}+0.5 \cdot \% \mathrm{Nb} .
\end{aligned}
$$

Metallographic etching reveals the microstructure and facilitates evaluation of phase composition (Fig. 3, 4, 5, 6 and 7). Groesbeck's reagent etches carbides heavily, ferrite a little less and leaves austenite pristine. With digital image analysis, the amount of austenite in the all-weld metal produced by GMA-SW is determined to $63.0 \%$ (Fig. 8, Table 3). With increasing dilution, the chromium equivalent decreases, while the nickel equivalent increases. However, it is interesting to see that the determined amount of austenite does not increase correspondingly, as would have been expected by the Schaeffler diagram: The highest 
Table 3 Dilution, chemical composition, chromium and nickel equivalents, and determined austenite content of the reference materials and the surface layer, and the respective surface welding parameters

\begin{tabular}{|c|c|c|c|c|c|c|c|c|c|c|c|c|}
\hline & & $\begin{array}{c}\text { Dilution, } \\
\%\end{array}$ & $\begin{array}{c}\mathrm{C}, \\
\mathrm{wt} \%\end{array}$ & $\begin{array}{l}\text { Mn, } \\
\text { wt } \%\end{array}$ & $\begin{array}{c}\mathrm{Cr}, \\
\mathrm{wt} \%\end{array}$ & $\begin{array}{l}\text { Mo, } \\
\text { wt\% }\end{array}$ & $\begin{array}{l}\mathrm{Ni}, \\
\mathrm{wt} \%\end{array}$ & $\begin{array}{c}\mathrm{N}, \\
\mathrm{wt} \%\end{array}$ & $\begin{array}{l}\mathrm{Fe}, \\
\mathrm{wt} \%\end{array}$ & $\begin{array}{c}\mathrm{Cr}_{\mathrm{eq}}, \\
\%\end{array}$ & $\begin{array}{c}\mathrm{Ni}_{\mathrm{eq}}, \\
\%\end{array}$ & $\begin{array}{c}\text { Austenite, } \\
\%\end{array}$ \\
\hline \multicolumn{2}{|c|}{ Gray cast iron } & $\ldots$ & 3.43 & 0.76 & 0.11 & 0.04 & 0.1 & $\ldots$ & 92.0 & 3.1 & 103 & $\ldots$ \\
\hline \multicolumn{2}{|c|}{ Duplex stainless steel } & $\ldots$ & 0.024 & 1.69 & 21.6 & 3.13 & 5.73 & 0.158 & 66.7 & 25.6 & 10.3 & 52.7 \\
\hline \multicolumn{13}{|c|}{ Gas metal arc surface welding } \\
\hline \multicolumn{2}{|c|}{ All-weld metal } & 0.0 & 0.022 & 1.69 & 22.7 & 3.14 & 8.73 & 0.146 & 62.9 & 26.6 & 10.3 & 63.0 \\
\hline $\begin{array}{l}\text { Shielding } \\
\text { gas }\end{array}$ & \multicolumn{12}{|c|}{ Preheating } \\
\hline $\mathrm{Ar}$ & None & 5.23 & 0.120 & 1.65 & 21.6 & 2.89 & 8.29 & 0.118 & 64.6 & 25.3 & 12.7 & 68.6 \\
\hline ArHe30 & None & 10.5 & 0.304 & 1.59 & 20.7 & 2.78 & 7.71 & 0.113 & 66.0 & 24.4 & 17.6 & 81.2 \\
\hline $\mathrm{He}$ & None & 30.8 & 0.982 & 1.32 & 15.8 & 2.06 & 6.21 & 0.103 & 72.4 & 19.2 & 36.3 & 72.8 \\
\hline $\mathrm{Ar}$ & $400{ }^{\circ} \mathrm{C}$ & 12.8 & 0.413 & 1.55 & 19.8 & 2.68 & 7.71 & 0.122 & 66.9 & 23.5 & 20.9 & 92.6 \\
\hline ArHe30 & $400{ }^{\circ} \mathrm{C}$ & 19.7 & 0.632 & 1.49 & 18.3 & 2.43 & 7.13 & 0.113 & 69.0 & 21.8 & 26.8 & 82.8 \\
\hline $\mathrm{He}$ & $400{ }^{\circ} \mathrm{C}$ & 42.2 & 1.312 & 1.23 & 13.3 & 1.73 & 5.23 & 0.099 & 75.8 & 16.7 & 45.2 & 69.2 \\
\hline \multicolumn{13}{|c|}{ Plasma transferred arc surface welding } \\
\hline \multicolumn{2}{|c|}{ Consumable (Ref 27) } & 0.0 & 0.029 & 1.20 & 23.4 & 3.22 & 5.66 & 0.150 & 65.3 & 27.8 & 7.14 & $\ldots$ \\
\hline $\begin{array}{l}\text { Shielding } \\
\text { gas }\end{array}$ & \multicolumn{12}{|c|}{ Preheating } \\
\hline $\mathrm{Ar}$ & None & 2.02 & 0.022 & 1.10 & 22.5 & 3.17 & 5.75 & 0.193 & 66.2 & 26.6 & 6.96 & 46.4 \\
\hline $\mathrm{Ar}$ & $200{ }^{\circ} \mathrm{C}$ & 3.25 & 0.051 & 1.07 & 22.1 & 3.12 & 5.70 & 0.189 & 66.6 & 26.3 & 7.77 & 47.0 \\
\hline $\mathrm{Ar}$ & $400{ }^{\circ} \mathrm{C}$ & 22.6 & 0.475 & 0.98 & 17.8 & 2.41 & 4.67 & 0.127 & 72.2 & 21.6 & 19.4 & 73.9 \\
\hline
\end{tabular}
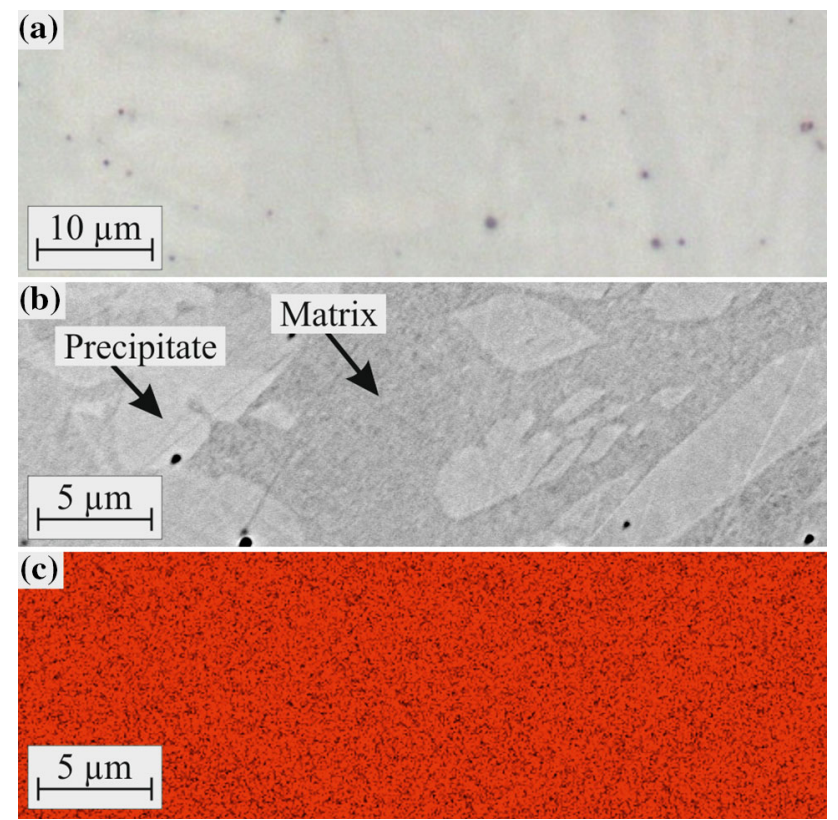

Fig. 3 Surface layer with a dilution of $2.02 \%$ (PTA-SW, argon gas, no preheating). (a) Optical microscopy etched with Groesbeck's reagent, (b) SEM image and (c) Cr concentration mapping (intensity of red is a function of $\mathrm{Cr}$ concentration) (Color figure online)
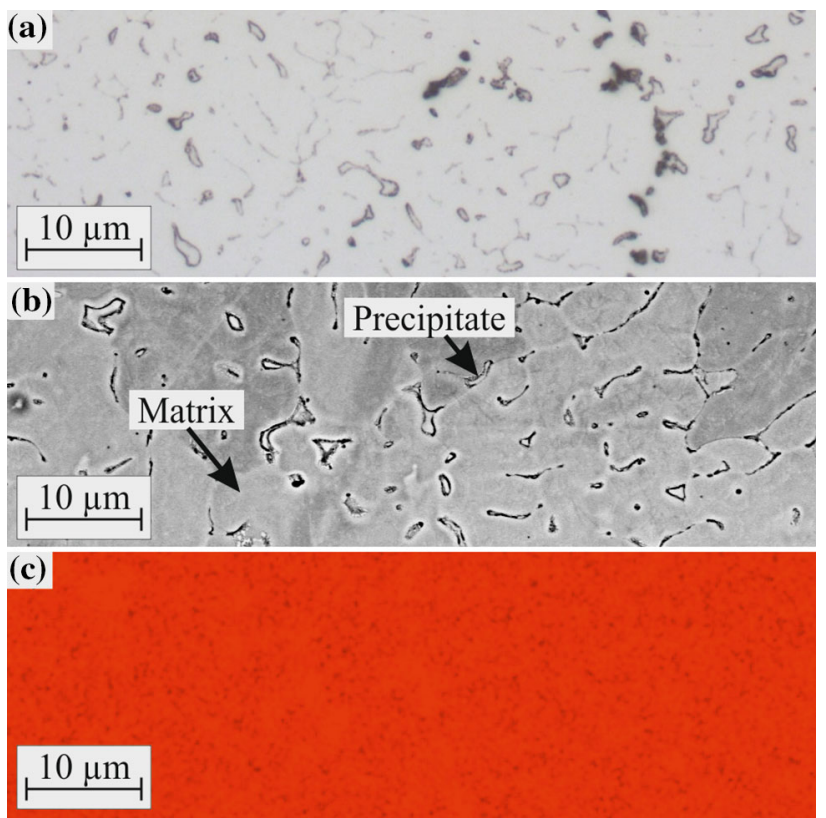

Fig. 4 Surface layer with a dilution of $10.5 \%$ (GMA-SW, argonhelium gas, no preheating). (a) Optical microscopy etched with Groesbeck's reagent, (b) SEM image, and (c) Cr concentration mapping (intensity of red is a function of $\mathrm{Cr}$ concentration) (Color figure online) 

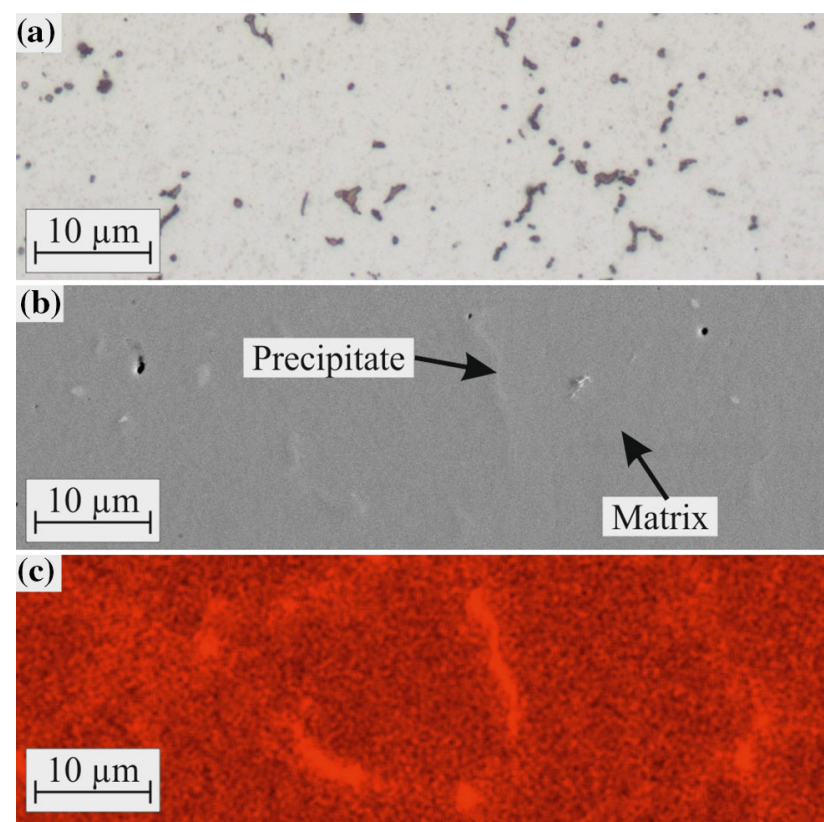

Fig. 5 Surface layer with a dilution of $12.8 \%$ (GMA-SW, argon gas, $400{ }^{\circ} \mathrm{C}$ preheating). (a) Optical microscopy etched with Groesbeck's reagent, (b) SEM image, and (c) Cr concentration mapping (intensity of red is a function of $\mathrm{Cr}$ concentration) (Color figure online)
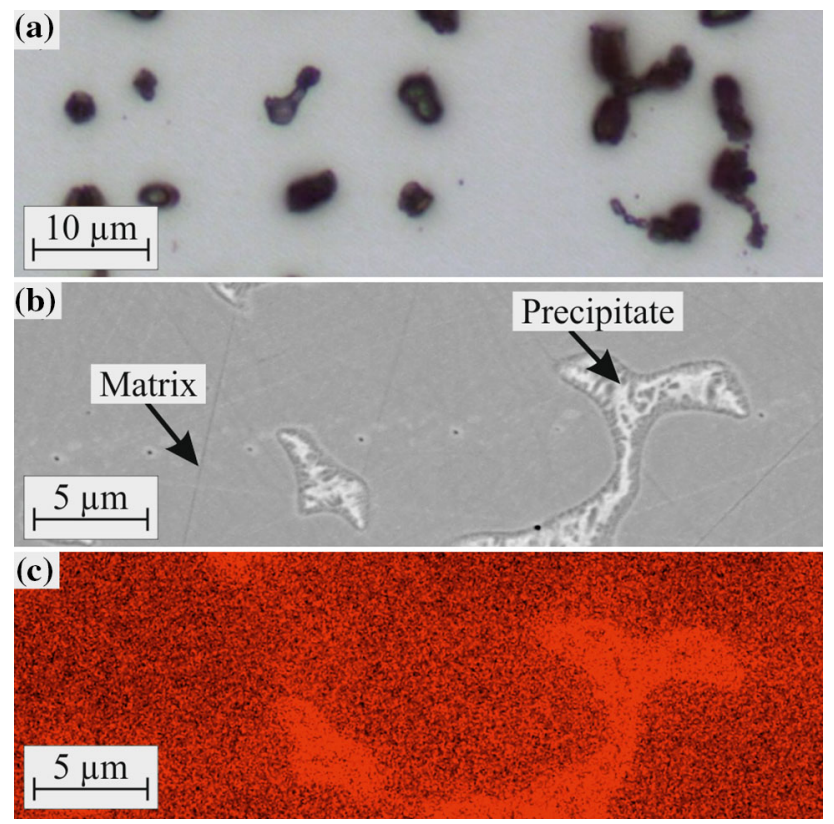

Fig. 6 Surface layer with a dilution of $22.6 \%$ (PTA-SW, argon gas, $400{ }^{\circ} \mathrm{C}$ preheating). (a) Optical microscopy etched with Groesbeck's reagent, (b) SEM image, and (c) $\mathrm{Cr}$ concentration mapping (intensity of red is a function of $\mathrm{Cr}$ concentration) (Color figure online)

amount of austenite was determined for the surface layer with a dilution of $12.8 \%$. Similar amounts of austenite $(81.2-82.8 \%)$ occur for very dissimilar dilutions of $10.5 \%$ and $19.7 \%$. The amount of austenite at highest dilution is only $69.2 \%$, contradicting the direct relationship between
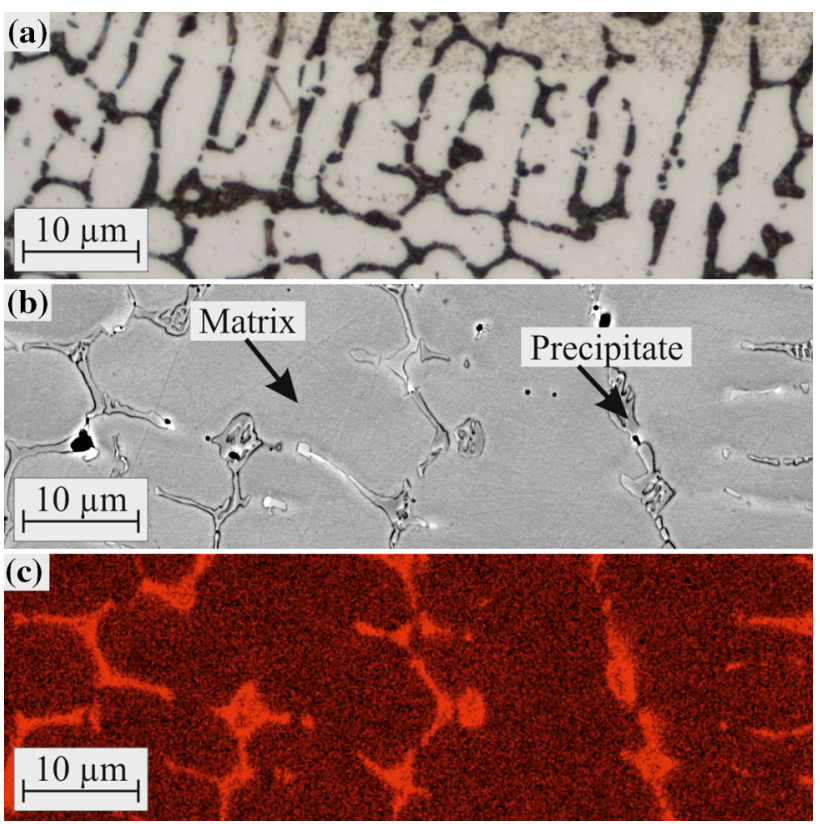

Fig. 7 Surface layer with a dilution of $42.2 \%$ (GMA-SW, helium gas, $400{ }^{\circ} \mathrm{C}$ preheating). (a) Optical microscopy etched with Groesbeck's reagent, (b) SEM image, and (c) Cr concentration mapping (intensity of red is a function of $\mathrm{Cr}$ concentration) (Color figure online)

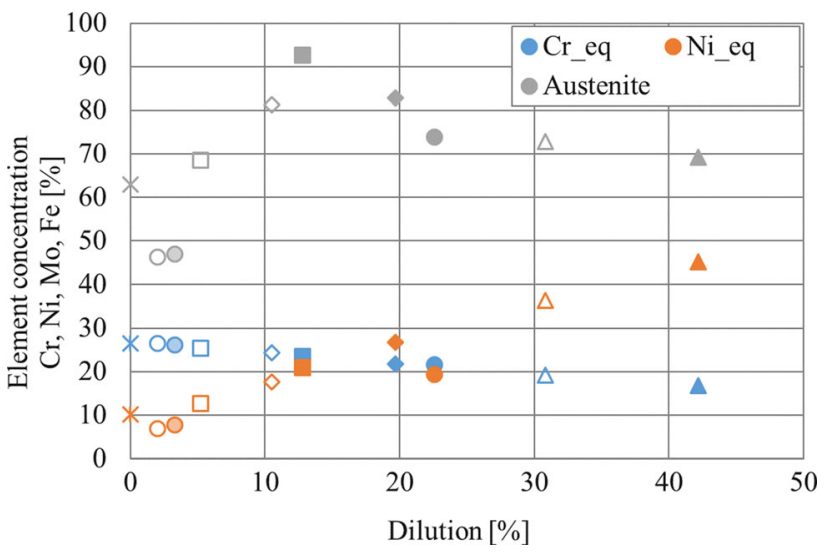

Fig. 8 Chromium and nickel equivalents and determined austenite content of the welded samples. Cross represents the all-weld metal, circles represent the plasma transferred arc welding, squares represent gas metal arc welding with argon, diamonds represent gas metal arc welding with argon-helium and triangles represent gas metal arc welding with helium. Filled symbols represent $400{ }^{\circ} \mathrm{C}$ preheating

dilution and amount of austenite that the Schaeffler diagram predicts. For GMA-SW without preheating, argonhelium gas results in the highest amount of austenite; however, with preheating to $400{ }^{\circ} \mathrm{C}$, the amount of austenite decreases with increasing helium content. For very low dilutions of the surface layers produced with PTA-SW welding, the amount of austenite is $46.4-47.0 \%$, which is close to that of the reference duplex stainless steel. 
At $22.6 \%$ dilution, the amount of austenite is $73.9 \%$, which is similar to the amount of austenite of the surface layer with $30.8 \%$ dilution produced with GMA-SW.

The austenite is only one constituent of the microstructure, which can also comprise ferrite, but carbides and other precipitates as well. To investigate the chemical composition of the phases found in the actual microstructure, EDX analyses were performed on selected spots of the matrix and the precipitates. For simplicity, the composition determined for the precipitates is normalized to the values determined for the matrix (Fig. 9, Table 4).

For the all-weld metal, the amount of ferrite-stabilizers chromium and molybdenum in the precipitates is lower than in the matrix $(<100 \%)$. Vice versa, the amount of austenite-stabilizer nickel in the precipitates is higher than in the matrix ( $>100 \%$ ), i.e., the microstructure comprises $63 \%$ austenite precipitates in a ferrite matrix, which is typical for welded duplex stainless steels of similar composition (Ref 23). The deviations between the elemental concentrations in the matrix and precipitates, that is the deviation of the introduced ratio from $100 \%$, are rather low, indicating a homogeneous distribution of elements. The surface layer with $2.02 \%$ dilution prepared by PTASW welding shows an even more homogeneous distribution of elements, with the ratio for iron even reaching balance. In the precipitates, the nickel concentration is a little higher, while chromium and molybdenum concentrations are lower, evidencing austenite in a ferrite matrix. Aside from an opposite trend in the carbon concentration, the same holds true for the surface layer with $3.25 \%$ dilution prepared by PTA-SW welding, where the homogeneity of the element distribution is a little less. There is a major change considering the samples with dilutions higher

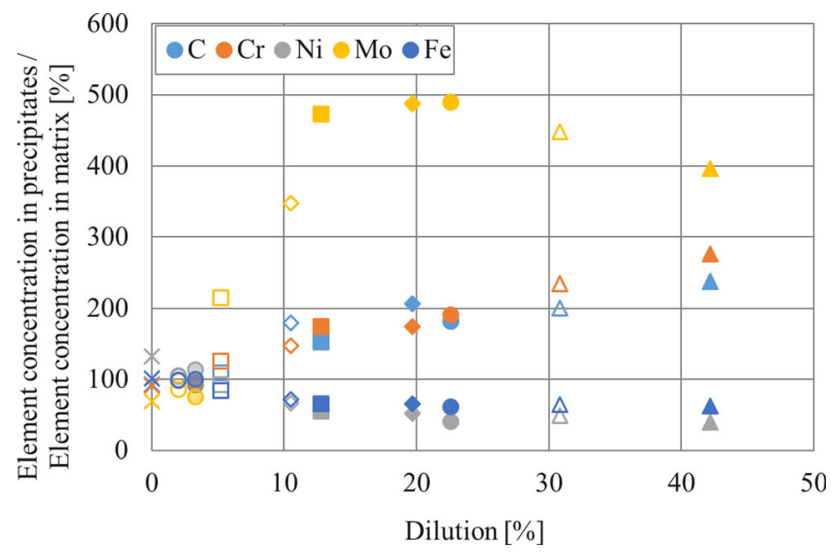

Fig. 9 Ratio of elemental concentration in the precipitates to the corresponding elemental concentration in the matrix, determined by EDX measurements. Cross represents the all-weld metal, circles represent the plasma transferred arc welding, squares represent gas metal arc welding with argon, diamonds represent gas metal arc welding with argon-helium and triangles represent gas metal arc welding with helium. Filled symbols represent $400{ }^{\circ} \mathrm{C}$ preheating than $5 \%$ with increasing ratios for molybdenum, carbon and chromium and decreasing ratios for iron and nickel (Fig. 9). While the increasing behavior of iron and nickel ratios confirms that it is mostly an austenite matrix, carbon and chromium ratios show similar, decreasing trends. Together with the strongly increased molybdenum content in the precipitates, it is a plausible assumption that the precipitates are chromium carbides and $\sigma$-phase (Ref 32).

This is proof that the composition, i.e., only the Schaeffler diagram cannot serve to estimate the resulting microstructure for the surface layers at hand. Firstly, the reason for this is the unaccounted influence of heat input and cooling rates by either preheating or the modifications to the heat distribution on the surface by additional helium in the shielding gas. Secondly, the Schaeffler diagram does not account for precipitation that evolves during cooling or elevated temperatures that are held after welding, i.e., postweld heat treatments.

For a better understanding of the microstructure, the metallographic cross sections etched with Groesbeck's reagent, SEM micrographs and EDX analysis of the surface layers with a dilution of $2.02 \%, 10.5 \%, 12.8 \%, 22.6 \%$ and $42.2 \%$ are qualitatively discussed to elaborate the influence of preheating and increasing helium content in the shielding gas on the microstructure of the surface layers.

The surface layer with a dilution of $2.02 \%$ (PTA-SW, argon gas, no preheating) comprises a ferrite matrix (light gray) with austenite grains (bright) and a few spherical inclusions (Fig. 3a). The ferrite matrix and austenite precipitates are more clear in the SEM image; the chromium concentration mapping taken at the same spot shows no variation in the chromium concentration between austenite and ferrite (Fig. 3b, c). Considering the presence of a ferrite matrix, it is probable that the weld pool solidified purely into $\delta$-ferrite and that upon rather rapid cooling, transformation into austenite occurred, while the rest of it remained as retained $\delta$-ferrite (Ref 33,34$)$. The cooling rate was apparently sufficiently high and post-weld heat input low, respectively, so that a ferrite-to-austenite ratio of approximately 54:46 could be obtained. The microstructures of the surface layers with $3.25 \%$ and $5.23 \%$ dilution showed a similar appearance, but slightly increasing austenite ratios due to the increasing amount of austenitestabilizing elements, e.g., carbon and nickel. In the microstructure of the surface layer with $5.23 \%$ dilution, very small carbide precipitates were observed.

For a dilution of $10.5 \%$ (GMA-SW, argon-helium gas, no preheating), the microstructure composes mainly austenite (bright) with ferrite (light brown) and a small amount of carbide precipitates (dark) that have the same morphology as the ferrite (Fig. 4a). This means that the cooling rates during surface welding were lower than in 
Table 4 Ratio of elemental concentration in the precipitates to the corresponding elemental concentration in the matrix, determined by EDX measurements

\begin{tabular}{lcccccccc}
\hline Process & Shielding gas & Preheating, ${ }^{\circ} \mathrm{C}$ & Dilution, $\%$ & $\mathrm{C}, \%$ & $\mathrm{Cr}, \%$ & $\mathrm{Ni}, \%$ & $\mathrm{Mo}, \%$ & $\mathrm{Fe}, \%$ \\
\hline GMA-SW & $\mathrm{Ar}$ & None & 0.0 & 93.7 & 91.7 & 133 & 69.2 & 102 \\
PTA-SW & $\mathrm{Ar}$ & None & 2.02 & 105 & 98.5 & 106 & 86.0 & 100 \\
PTA-SW & $\mathrm{Ar}$ & 200 & 3.25 & 92.1 & 97.1 & 114 & 76.1 & 101 \\
GMA-SW & $\mathrm{Ar}$ & None & 5.23 & 109 & 126 & 92.5 & 215 & 84.2 \\
GMA-SW & $\mathrm{ArHe} 30$ & None & 10.5 & 180 & 147 & 66.8 & 348 & 72.1 \\
GMA-SW & $\mathrm{Ar}$ & 400 & 12.8 & 153 & 174 & 55.6 & 473 & 65.9 \\
GMA-SW & $\mathrm{ArHe} 30$ & 400 & 19.7 & 207 & 174 & 52.4 & 488 & 66.0 \\
PTA-SW & $\mathrm{Ar}$ & 400 & 22.6 & 182 & 191 & 40.5 & 490 & 61.4 \\
GMA-SW & $\mathrm{He}$ & None & 30.8 & 200 & 235 & 48.7 & 448 & 64.4 \\
GMA-SW & $\mathrm{He}$ & 400 & 42.2 & 238 & 276 & 39.9 & 396 & 62.6 \\
\hline
\end{tabular}

PTA-SW without preheating, but high enough to conserve a little amount of ferrite. The carbides precipitated from the ferritic phase. Possibly, the heat input by an increased thermal conductivity of the argon-helium shielding gas facilitated diffusion of carbon and chromium in the austenite to the grain boundaries. Then, a phase transformation from ferrite to carbide occurred. However, the mapping of the chromium concentration does not indicate any apparent color differences, i.e., the chromium distribution is rather homogeneous, which is also confirmed by a relative chromium concentration of $147 \%$ in the precipitates (Fig. 4b, c, Table 4).

At a dilution of $12.8 \%$ (GMA-SW, argon gas, $400{ }^{\circ} \mathrm{C}$ preheating), the microstructure seems to comprise only austenite (light) and carbide precipitates (dark) (Fig. 5a). The EDX mapping indicates obvious differences in the chromium concentration between the matrix (dark red) and precipitate (light red) (Fig. 5b, c). It is assumed that preheating greatly enhanced diffusion processes, especially the diffusion of carbon and chromium from the austenite matrix to the grain boundaries. There, phase transformations took place, converting any remaining ferrite to chromium carbide with a relative chromium concentration of $174 \%$.

With a dilution of $22.6 \%$ (PTA-SW, argon gas, $400{ }^{\circ} \mathrm{C}$ preheating), the microstructure comprises only austenite (bright) and carbide precipitates (dark) that appear evenly distributed in the austenite matrix (Fig. 6a). The precipitates are distinctly observed in the SEM image and enriched with $191 \%$ relative chromium concentration compared to the surrounding matrix (Fig. 6b, c, Table 4). At such dilutions, great amounts of the liquid weld pool solidified probably mostly austenitic and any retained ferrite transformed into carbide, enabled by prolonged heating after the welding. During the extended heating time, diffusion of carbon and chromium facilitates the growth of the carbide precipitates.

A dilution of $42.2 \%$ (GMA-SW, helium gas, $400{ }^{\circ} \mathrm{C}$ preheating) provides large amounts of carbon in the surface layer. It also influences the solidification of the liquid weld pool in such a way that carbides may form directly from the melt, resulting in the observed dendritic microstructure (Fig. 7a). The high heat input caused by the chosen process parameters provides sufficient energy to facilitate diffusion of both carbon and chromium to the phase boundaries. Subsequently, by maintaining the preheating temperature and lowered cooling rates, large amounts of carbide grow and interconnect into a dense, chromium enriched network, which renders the chromium mapping very clear (Fig. 7b, c). The intense red colors represent the high-chromium phase and the darker red corresponds to the austenite. That network very sharply separates the individual austenite phases.

With increasing dilution, the primary solidification changes from ferritic into more austenitic character, and upon decreasing cooling rates and increasing preheating temperatures, more carbon is available for carbide formation (Table 3) (Ref 33). Increasing heat input by preheating and a wider heat distribution by adding helium to the shielding gas facilitate diffusion and phase transformations. From evenly balanced austenite and ferrite phases at 2.02\% dilution, a transformation of the ferrite phase into carbides is observed at $10.5 \%$ dilution which was enabled through the broader heat distribution on the surface produced by the higher conductivity of the argon-helium mixture shielding gas. Complete transformation of the ferrite into austenite and carbides at $12.8 \%$ dilution was enabled through the preheating temperature of $400{ }^{\circ} \mathrm{C}$ which was held after the welding. Similarly, at $22.6 \%$ dilution, the carbides in an otherwise purely austenitic matrix have grown larger. Eventually, a very pronounced, highly interconnected carbide network, which confines individual austenitic phases, forms at a dilution of $42.2 \%$. The ratio of chromium in the precipitates compared to the austenite phases is $276 \%$. This means that on the one hand, there is chromium enrichment in the precipitates, while on the other hand, there is a considerable chromium depletion in the phase boundaries of the austenite. 
Increasing amounts of carbon stabilize austenite formation because of the lower carbon solubility limit of ferrite. However, for dilutions of the surface layers with a dilution above $12 \%$ (which corresponds to $0.4 \%$ carbon), the risk of carbide precipitation increases. The amount of carbides in the surface layer with a dilution of $12.8 \%$ (GMA-SW, argon gas, $400{ }^{\circ} \mathrm{C}$ preheating) is comparably low. This is the result of low thermal conductivity of pure argon, resulting in a narrow heat distribution on the surface and applied preheating temperatures. Cooling rates are low and heat input is high; thus, extensive austenite formation occurs $(92.6 \%)$.

For GMA-SW, interconnection of the precipitates, i.e., a carbide network, does occur already at a dilution of $19.7 \%$, (argon-helium gas, $400{ }^{\circ} \mathrm{C}$ preheating), and for a dilution of $30.8 \%$ (helium gas, no preheating), but not for a dilution of $12.8 \%$ (argon gas, $400{ }^{\circ} \mathrm{C}$ preheating) (Fig. 5). For PTA-SW, however, at a dilution of $22.6 \%$ (argon gas, $400{ }^{\circ} \mathrm{C}$ preheating), no interconnected carbide network was observed, which may again be explained by a narrow heat distribution, except that in this case, this narrow heat distribution is the result of the columnar arc that intrinsically does not affect formerly welded areas as much as does the conical arc of the GMA-SW process (Fig. 6).

Thus, it appears that the microstructure is not only determined by the dilution, but also by the width of the heat treated area, that is the surface area, where diffusion and phase transformation are excited by a wider heat distribution through the shape of the arc or through an increased heat conductivity of the shielding gas obtained by helium addition.

In summary, the microstructures of the surface layers with dilutions up to $3.25 \%$ comprise ferrite and austenite, while up to $10.5 \%$ austenite, ferrite and small amounts of carbides compose the microstructure. At a dilution higher than $12.8 \%$, ferrite is not found in the microstructures anymore, which is instead composed of austenite and carbide precipitates. The amount of carbide precipitates increases for the surface layers with increasing dilution. At dilutions of $30.8 \%$ and $42.2 \%$, a carbide network that confines austenite grains is observed.

\section{Corrosion Testing}

\section{Potentiodynamic Polarization}

Photographs of the sample surfaces were taken after the potentiodynamic polarization test (Fig. 10). The surface of gray cast iron is extensively corroded after the potentiodynamic polarization, while the reference duplex stainless steel, the all-weld metal (GMA-SW) and the surface layer with $2.02 \%$ dilutions did not corrode (Fig. 10a-d). Every surface layer with dilution higher than $3.25 \%$ exhibited corrosion in the test, which is evident by various corrosion marks on the surface layers after the test (Fig. 10e-1). On the surface layer with $3.25 \%$ dilution, there are a few traces of corrosion at the transition between the test zone and the outer zone that was covered by the galvanic tape. The surface layers with dilutions of $5.23 \%$ and $10.5 \%$ are partially covered with corrosion products, and few local corrosion marks are visible. Two straight-line features and a ring-shaped feature appear on the surface layer with a dilution of $12.8 \%$. At a dilution of $19.7 \%$, the surface is covered with corrosion products and crevice corrosion is observed. A similar appearance can be observed on the surface layer with $22.6 \%$ dilution. Distinct corrosion in a ring-shape and some local corrosion occurred on the surface layers with dilutions of $30.8 \%$ and $42.2 \%$. All surface layers corroded less than the gray cast iron.

This gives qualitative information about the corrosion appearance, but current density-polarization curves allow for comparison of the different open circuit potentials and the corrosion kinetics, e.g., the formation and breakdown of a passive layer.

The open circuit potential of the all-weld metal (GMA$\mathrm{SW}$ ) is about $470 \mathrm{mV}$ more positive, i.e., nobler, compared to the lamellar gray cast iron (EN-GJL-250) (Fig. 11). The steep increase in current density after passing the open circuit potential for lamellar gray cast iron is typical for active corrosion. The extended plateau at low values of current density after passing the open circuit potential of the all-weld metal is typical for the formation of a passive layer. The plateau extends for about $1100 \mathrm{mV}$, until the current density increases sharply, indicating the (local) breakdown of the passive layer.

The current density-potential curves of the GMA-SW surface layers are between gray cast iron and the all-weld metal (GMA-SW), which confirms the visual examination. The open circuit potentials are almost identical to that of the all-weld metal (GMA-SW), except for those of the surface layers with dilutions of $30.8 \%$ and $42.2 \%$ (helium gas). For the surface layer with a dilution of $5.23 \%$ (argon gas, no preheating), the passive region extends over $400 \mathrm{mV}$ and $200 \mathrm{mV}$ for the surface layer with a dilution of $10.5 \%$ (argon-helium gas, no preheating), respectively. The surface layers with dilution of $12.8 \%$ and $19.7 \%$ do not show extended passivity, but characteristics of active corrosion, i.e., a sharp increase in current directly after passing the open circuit potential. The same behavior is found for the surface layers with $30.8 \%$ and $42.2 \%$ dilution; however, they have more negative, i.e., less noble, open circuit potentials, which are still far more noble than that of gray cast iron (Fig. 11).

To facilitate the assessment of the PTA-SW surface layers, especially the ones with very low dilution, the respective current density-potential curves are compared to 
Fig. 10 Photographs of the test zones after potentiodynamic polarization measurement (Color figure online)
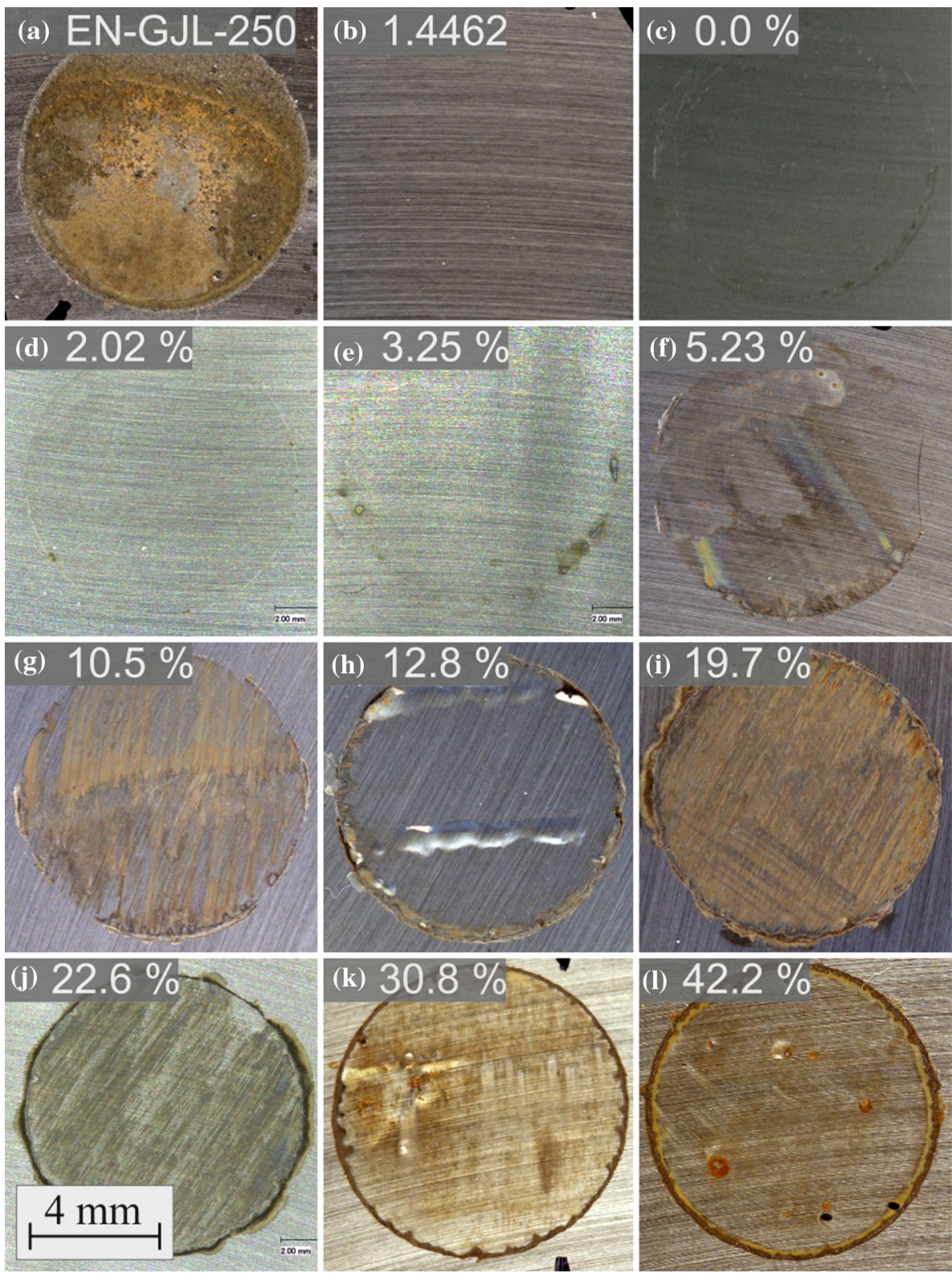

the curves of the GMA-SW surface layers that showed passive behavior, i.e., $5.23 \%$ and $10.5 \%$ dilution, the allweld metal (GMA-SW) and a commercially available duplex stainless (1.4462) (Fig. 12). The 1.4462 has an open circuit potential similar to the all-weld metal (GMA-SW), but its passive region has a slightly higher extension compared to the all-weld metal (GMA-SW). In fact, all PTA-SW surface layers have an open circuit potential close to that of the duplex stainless steel and all exhibit a passive region. The passive region is shortest for the surface layer with $22.6 \%$ dilution. After that passive region, the current density increases sharply, which indicates active corrosion. The extension of the passive region of the surface layer with $3.25 \%$ dilution is almost twice as wide compared to
5.23\% dilution, after which the current increases moderately. Lastly, the current density-potential curve of the surface layer with $2.02 \%$ dilution is similar to the curve of the all-weld metal (GMA-SW) up to the very end of the $1100 \mathrm{mV}$ passive region which is comparable to the duplex stainless steel (Fig. 12).

\section{Immersion and Electrochemical Impedance Spectroscopy}

After $24 \mathrm{~h}$ of immersion followed by EIS measurement, the surface of gray cast iron is completely corroded, while there is no corrosion observed for the duplex stainless steel, the all-weld metal (GMA-SW) and the surface layers with dilution of up to $10.5 \%$ (Fig. 13). The surface layers with 


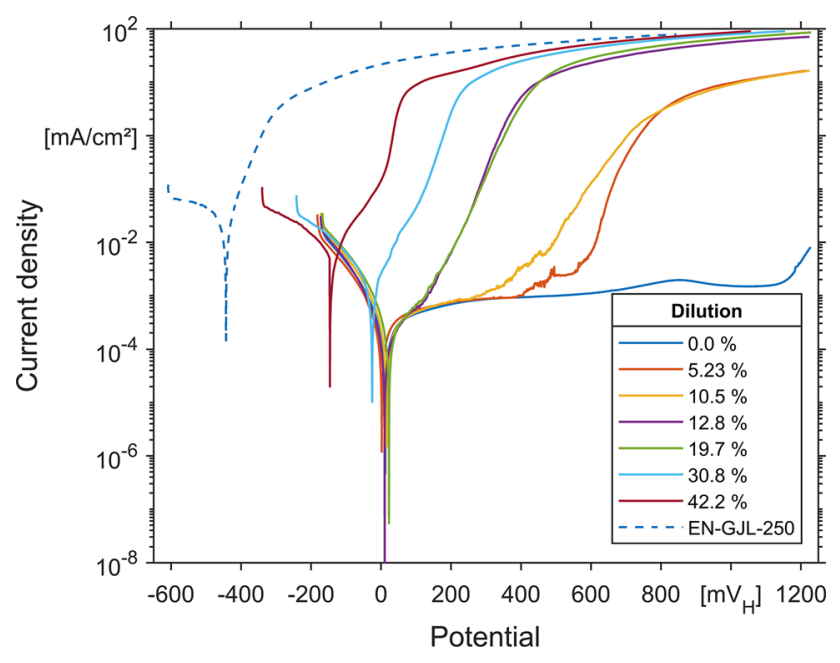

Fig. 11 Current density-potential curves of GMA-SW surface layers and reference materials (0.0\%: all-weld metal) (Color figure online)

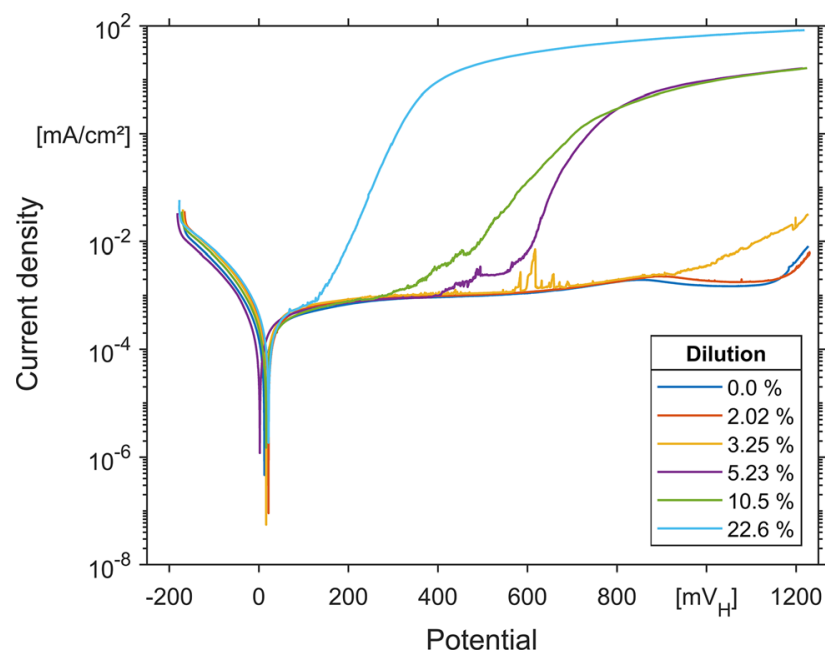

Fig. 12 Current density-potential curves of PTA-SW surface layers and low dilution GMA-SW surface layers $(5.23 \%$ and $10.5 \%)$ and reference materials all-weld metal (GMA-SW, 0.0\%) and duplex stainless steel (1.4462) (Color figure online)

dilutions of $12.8 \%, 19.7 \%, 22.6 \%$ and $30.8 \%$ show few corrosion pits. On the surface layer with a dilution of $42.2 \%$, there is a large number of corrosion marks.

Pitting corrosion on the surface layer with dilution of $12.8 \%$ and higher seems to initiate preferably in a linearly stretched area (especially Fig. 13h, k). The images are arranged in such a way that, for the surface layers, the weld direction is approximately horizontal. By visual inspection of the cross section of the samples, it is clear that this area corresponds to the transition between two weld beads.

In contrast to the potentiodynamic polarization measurements, no crevice corrosion is observed during immersion followed by EIS measurement, but only pitting corrosion. This implies that some protective layer, which is locally penetrated during immersion, can form on all surface layers (Ref 35). It also proves the less destructive character of the immersion and EIS measurement compared to potentiodynamic polarization. The Bode plot obtained by the EIS measurements provides characteristics, e.g., the impedance magnitude (solid lines, left y-axis) and the phase shift (dashed lines, right $y$-axis), of the layers after $24 \mathrm{~h}$ of immersion (Fig. 14, 15).

For low dilutions, the maximum phase shift increases, which is an indication of a more capacitor-like response of the passive film formed on the surface layer. At low frequencies, the impedance magnitude increases for decreasing dilution (at low frequencies, this gets close to an ohmic resistance, which is the charge transfer resistance). A high charge transfer resistance and capacitor-like behavior are inherent to an insulating passive film.

Fitting the results from the EIS measurements to the equivalent circuit of a simplified Randles cell provides values for the solution resistance $R_{\mathrm{s}}$, the charge transfer resistance $R_{\mathrm{ct}}$ and the double-layer capacitance $C_{\mathrm{dl}}$ (Fig. 2, 16, Table 5). The solution resistance is constant. The charge transfer resistance decreases for increasing dilution. This corresponds to a less protective passive film or an increasingly compromised passive film. The higher the charge transfer resistance, the more hindered is any (electro-) chemical reaction between sample and electrolyte. There is a significant step in the charge transfer resistance of roughly two orders of magnitude between $10.5 \%$ and $12.8 \%$ dilution (Fig. 16). This is in exact agreement with the phenomenological difference in the corrosion behavior that is visually observed after the measurement, where the surface layer with $12.8 \%$ dilution corroded locally but the surface layer with $10.5 \%$ dilution did not (Fig. 13g, h). From this result, it is safe to say that the surface layers with dilutions below $10.5 \%$ are capable of forming a dense and stable passive layer under the applied test conditions.

The double-layer capacitance is minimum for the surface layers with dilutions of $5.23 \%$ and $10.5 \%$ and then increases with the dilution. The increase in the capacitance may result from a thinner dielectric film (the passive film). Due to corrosion, resulting in an electrochemically unstable system, the application of the determined values for the description of that system is questionable as there are many factors involved, e.g., the size of active corrosion sites and the area of passive surface.

In general, the results from the combined immersion and EIS measurement describe the effect of both dilution and carbide precipitates: On the one hand, increasing dilutions reduce the amount of chromium available to passive layer formation. On the other hand, chromium is bound in carbide precipitates, further reducing the available amount of chromium. Thus, increasing levels of dilution and carbide 
Fig. 13 Photographs of the test zones after $24 \mathrm{~h}$ immersion and EIS measurement (Color figure online)
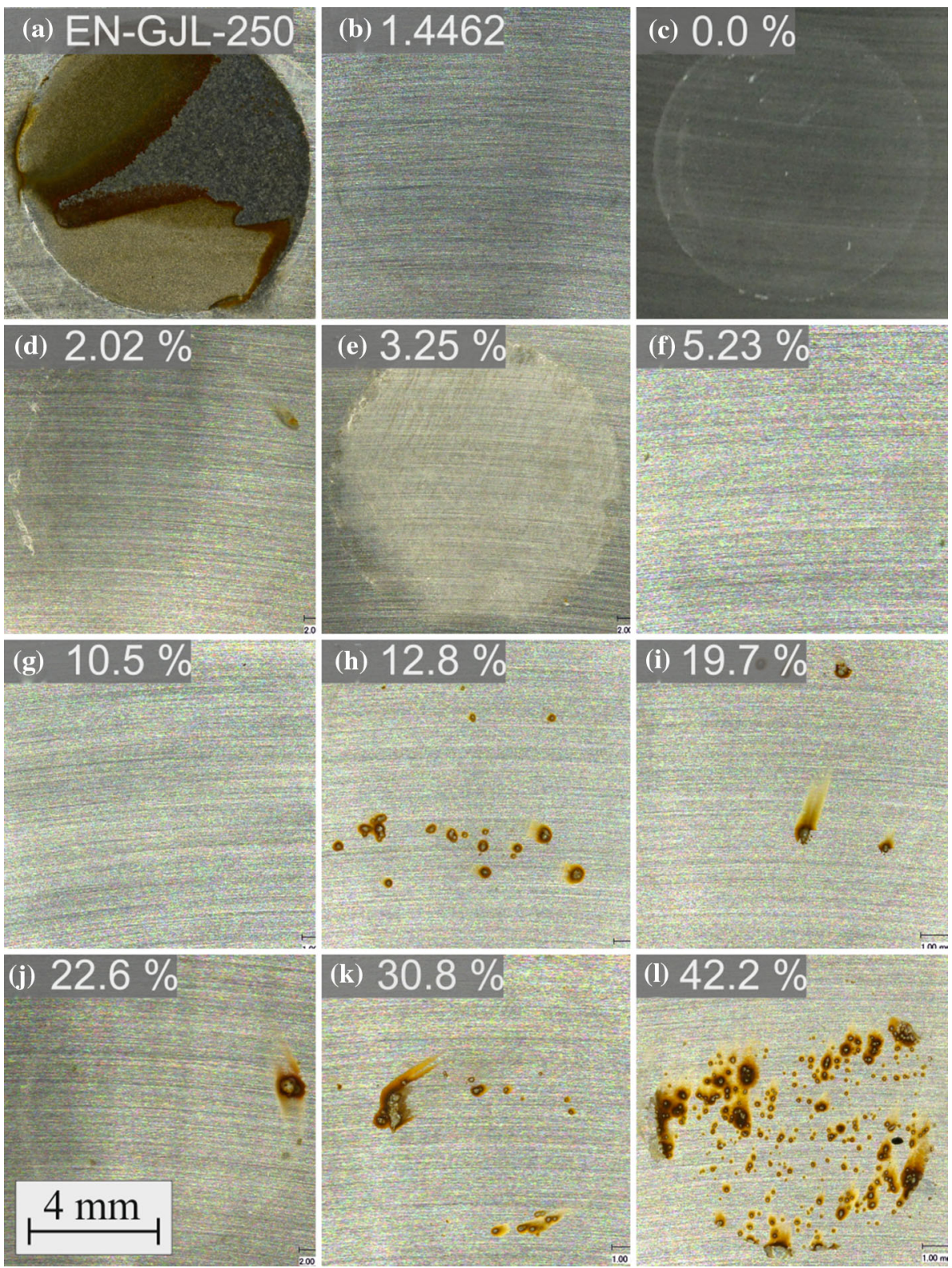

precipitates in the microstructure lead to reduced corrosion resistance of the surface layers even under immersion conditions.

\section{Investigation of the Corrosion Mechanisms After Potentiodynamic Polarization Measurement}

SEM micrographs and EDX analyses are used to investigate the corrosion mechanisms that occurred during the electrochemical polarization measurements. Exemplarily, the surface layers with a dilution of $10.5 \%$ (GMA-SW, argon-helium gas, no preheating), $12.8 \%$ (GMA-SW, argon gas, $400{ }^{\circ} \mathrm{C}$ preheating), $22.6 \%$ (PTA-SW, argon gas, $400{ }^{\circ} \mathrm{C}$ preheating) and $42.2 \%$ (GMA-SW, helium gas,
$400{ }^{\circ} \mathrm{C}$ preheating), whose microstructures were already discussed, are chosen to represent the influence of dilution and microstructure on the corrosion mechanism (Fig. 17).

The corrosion on the surface layer with a dilution of $10.5 \%$ (GMA-SW, argon-helium gas, no preheating) occurred locally, i.e., the greatest part of the surface remained passive. The chromium enrichment in the precipitates is $147 \%$ compared to the matrix. Local corrosion attacked mainly the phase boundaries of austenite (Fig. 17a). More distributed local corrosion occurred on the surface layer with a dilution of $12.8 \%$ (GMA-SW, argon gas, $400{ }^{\circ} \mathrm{C}$ preheating). The phase boundaries between the austenite and the precipitates corroded selectively and holes opened up for the corrosive medium to enter 


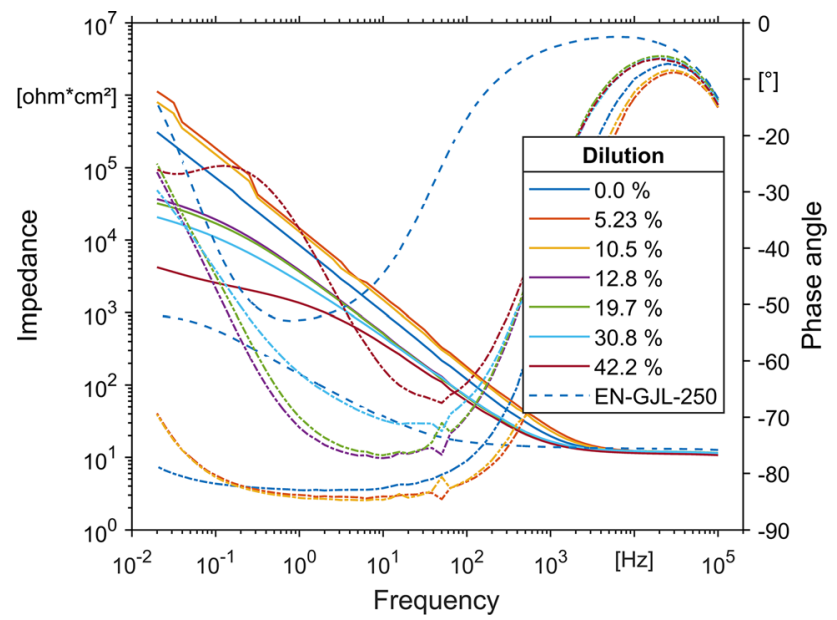

Fig. 14 Bode plot after $24 \mathrm{~h}$ immersion and EIS measurement of GMA-SW surface layers and reference materials (0.0\%: all-weld metal) (Color figure online)

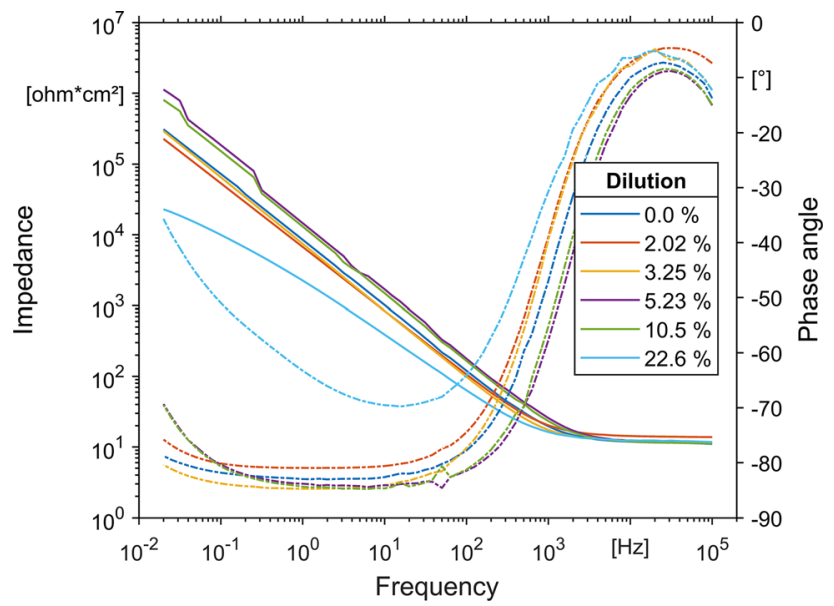

Fig. 15 Bode plot after $24 \mathrm{~h}$ immersion and EIS measurement of PTA-SW-welded surface layers and low dilution GMA-SW surface layers $(5.23 \%$ and $10.5 \%)$ and reference materials all-weld metal (GMA-SW, 0.0\%) and duplex stainless steel (1.4462) (Color figure online)

(Fig. 17b). Below the surface, oxygen depletion and acidification lead to more aggressive corrosion conditions comparable to crevice corrosion (Ref 35). The corrosion mechanism that occurred on the surface layer with $22.6 \%$ dilution also selectively attacked the phase boundary between the carbide precipitates and the austenite (Fig. 17c). It can be seen that a very thin layer between these two phases was dissolved and that corrosion of the austenite grains stopped after that. That same corrosion mechanism is more pronounced at a dilution of $42.2 \%$ (GMA-SW, helium gas, $400{ }^{\circ} \mathrm{C}$ preheating), where the surface was undercut from corrosion to such an extent, that the top layer almost lost connection to the bulk. The corrosion proceeded along the chromium-depleted phase boundaries deeper into the surface layer (Fig. 17d). The

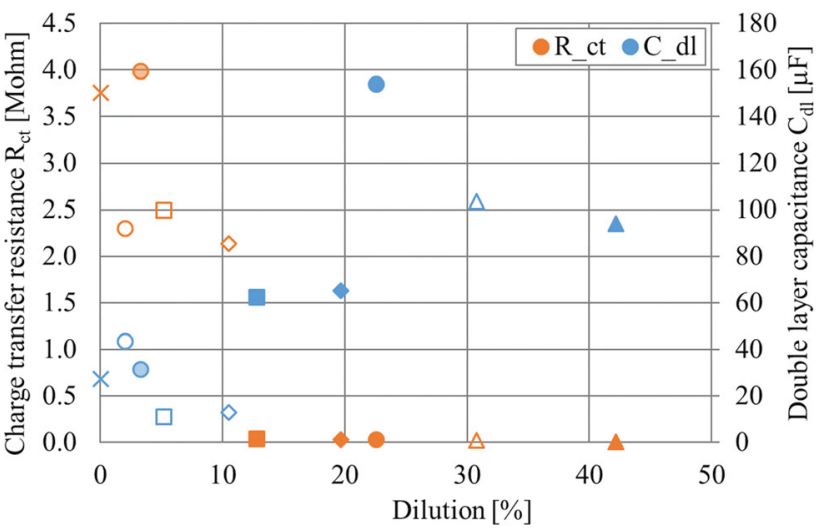

Fig. 16 Extracted data from EIS measurement after $24 \mathrm{~h}$ immersion of surface layers and all-weld metal (GMAW, 0.0\%). $R_{\mathrm{s}}$ : solution resistance, $R_{\mathrm{ct}}$ : charge transfer resistance and $C_{\mathrm{dl}}$ : double-layer capacitance. Cross represents the all-weld metal, circles represent the plasma transferred arc welding, squares represent gas metal arc welding with argon, diamonds represent gas metal arc welding with argon-helium and triangles represent gas metal arc welding with helium. Filled symbols represent $400{ }^{\circ} \mathrm{C}$ preheating (Color figure online)

austenite grains were attacked only at their phase boundary, where the local chromium concentration was lowest. The corrosion stopped at the inner part of the austenite, where the chromium concentration is high enough for corrosion resistance.

Potentiodynamic polarization measurements in artificial seawater yield that increasing dilution reduces the corrosion resistance of the surface layers. The chromium-depleted phase boundaries corroded selectively. This mechanism gets more intense with higher chromium enrichment in the precipitates and is most severe for an interconnected carbide network.

\section{Conclusion}

It is clear that the dilution determines the corrosion resistance of the surface layers, while the microstructure seems to determine the corrosion mechanism. To clearly distinguish between the two effects, the conclusion is subdivided into three parts that describe the influence of the dilution and the microstructure on the corrosion resistance at first separately, and finally, the corrosion resistance of the surface layers is regarded as a result from the welding process that produces the respective dilutions and microstructures.

\section{Influence of Dilution on Corrosion Resistance}

As evident from the potentiodynamic polarization measurements, the dilution of the consumable (duplex stainless steel) with the base material (gray cast iron) has a strong influence on the corrosion resistance and the ability to form 
Table 5 Extracted data from EIS measurement after $24 \mathrm{~h}$ immersion of surface layers and reference materials all-weld metal (GMA-SW, 0.0\%) and duplex stainless steel (1.4462)

\begin{tabular}{llccccc}
\hline Process & Shielding gas & Preheating, ${ }^{\circ} \mathrm{C}$ & Dilution, $\%$ & $R_{\mathrm{s}}$, ohm & $R_{\mathrm{ct}}, \mathrm{Mohm}$ & $C_{\mathrm{dl}}, \mu \mathrm{F}$ \\
\hline 1.4462 & $\ldots$ & $\ldots$ & $\ldots$ & 12.1 & 1.576 & 42.26 \\
GMA-SW & $\mathrm{Ar}$ & None & 0.0 & 11.4 & 3.759 & 27.40 \\
PTA-SW & $\mathrm{Ar}$ & None & 2.02 & 13.9 & 2.300 & 43.70 \\
PTA-SW & $\mathrm{Ar}$ & 200 & 3.25 & 12.1 & 3.992 & 31.75 \\
GMA-SW & $\mathrm{Ar}$ & None & 5.23 & 11.8 & 2.490 & 11.16 \\
GMA-SW & $\mathrm{ArHe} 30$ & None & 10.5 & 11.5 & 2.141 & 13.09 \\
GMA-SW & $\mathrm{Ar}$ & 400 & 12.8 & 11.4 & 0.040 & 62.49 \\
GMA-SW & $\mathrm{ArHe} 30$ & 400 & 19.7 & 11.7 & 0.033 & 65.20 \\
PTA-SW & $\mathrm{Ar}$ & 400 & 22.6 & 11.4 & 0.031 & 154.0 \\
GMA-SW & $\mathrm{He}$ & None & 30.8 & 11.2 & 0.023 & 103.5 \\
GMA-SW & $\mathrm{He}$ & 400 & 42.2 & 10.3 & 0.003 & 93.93 \\
EN-GJL-250 & $\ldots$ & $\ldots$ & $\ldots$ & 13.2 & 0.001 & 2443 \\
\hline
\end{tabular}

$R_{\mathrm{s}}$ solution resistance, $R_{\mathrm{ct}}$ charge transfer resistance, $C_{\mathrm{dl}}$ double-layer capacitance stable passive films. The all-weld metal (GMA-SW) and the surface layer with $2.02 \%$ dilution exhibit stable passivity over $1100 \mathrm{mV}$ which is almost similar to the commercially available duplex stainless steel. A dilution of $3.25 \%$ is already enough to decrease the extent of the passive region to about $950 \mathrm{mV}$, while a dilution of 5.23\% shrinks the passive region to only $400 \mathrm{mV}$. A dilution of $10.5 \%$ further reduces the passive region to $200 \mathrm{mV}$. Although no passive region is observed for the GMA-SW surface layers with dilutions higher than $12.8 \%$, the PTASW surface layer with $22.6 \%$ dilution exhibits a thin passive region of approximately $120 \mathrm{mV}$. After passive film breakdown, every surface layer, except for the PTA-SW surface layer with $2.02 \%$ dilution, shows localized corrosion.

The electrochemical impedance spectroscopy measurements are less aggressive and allow for some degree of passive film formation on all surface layers. However, after $24 \mathrm{~h}$ of immersion followed by that measurement, pitting corrosion occurred for all surface layers with dilution of $12.8 \%$ and higher. The PTA-SW surface layer with $22.6 \%$ dilution which showed a passive region in the potentiodynamic polarization measurement corroded locally in that test as well, i.e., the passive layer is only (completely) stable for a certain amount of time. The charge transfer resistance decreased for increasing dilution, i.e., that the passive film formation is most efficient for low dilutions. A sharp decrease over two orders of magnitude in the charge transfer resistance marks the failure of the passive layer.

\section{Influence of Microstructures on Corrosion Mechanisms}

The corrosion pits observed after the $24 \mathrm{~h}$ immersion and EIS measurement initiated from the transition area between two weld beads. This is the area, where a weld bead was (partially) melted again and an extra amount of heat was put into the bead. This additional heat input leads to increased diffusion and precipitation of carbides. After the potentiodynamic measurements, cross sections were prepared and analyzed with SEM and EDX to determine the corrosion mechanism: Surrounding the (highly) chromium enriched carbide precipitates, there is a narrow strip of chromium-depleted austenite, which is highly susceptible to corrosion. This chromium-depleted phase boundary corrodes preferentially. That mechanism was detected for all surface layers with a dilution higher than $5.23 \%$, but the intensity increased strongly with the amount of carbide precipitates. The selective corrosion attack was most severe for the surface layers with an interconnected carbide network, where the corrosion penetrated the surface, proceeded intergranularly and then continued below the surface similar to crevice corrosion. A homogeneous distribution of the elements between the precipitates and the matrix prevents that corrosion mechanism under the applied test conditions.

\section{Influence of Welding Process Parameters on Corrosion Behavior}

Preheating of the sample during the surface layer process lowers the cooling rates and keeps the surface layer and the base material at an elevated temperature. The result is increased dilution and prolonged diffusion time. For the surface layers that were preheated to $400{ }^{\circ} \mathrm{C}$, this leads to formation of chromium carbides, and thus, these surface layers had less corrosion resistance. For the PTA-SW surface layer that was preheated to $200{ }^{\circ} \mathrm{C}$, which also still had a very low dilution of $3.25 \%$, an effect of slowed cooling rates or prolonged diffusion times after the welding on the microstructure compared to the PTA-SW surface layer with no preheating was not observed. 
Fig. 17 SEM images (left) and $\mathrm{Cr}$ concentration mappings (right) for the surface layer with a dilution of (a) $10.5 \%$,

(b) $12.8 \%$, (c) $22.6 \%$ and

(d) $42.2 \%$ (intensity of red is a

function of $\mathrm{Cr}$ concentration)

(Color figure online)
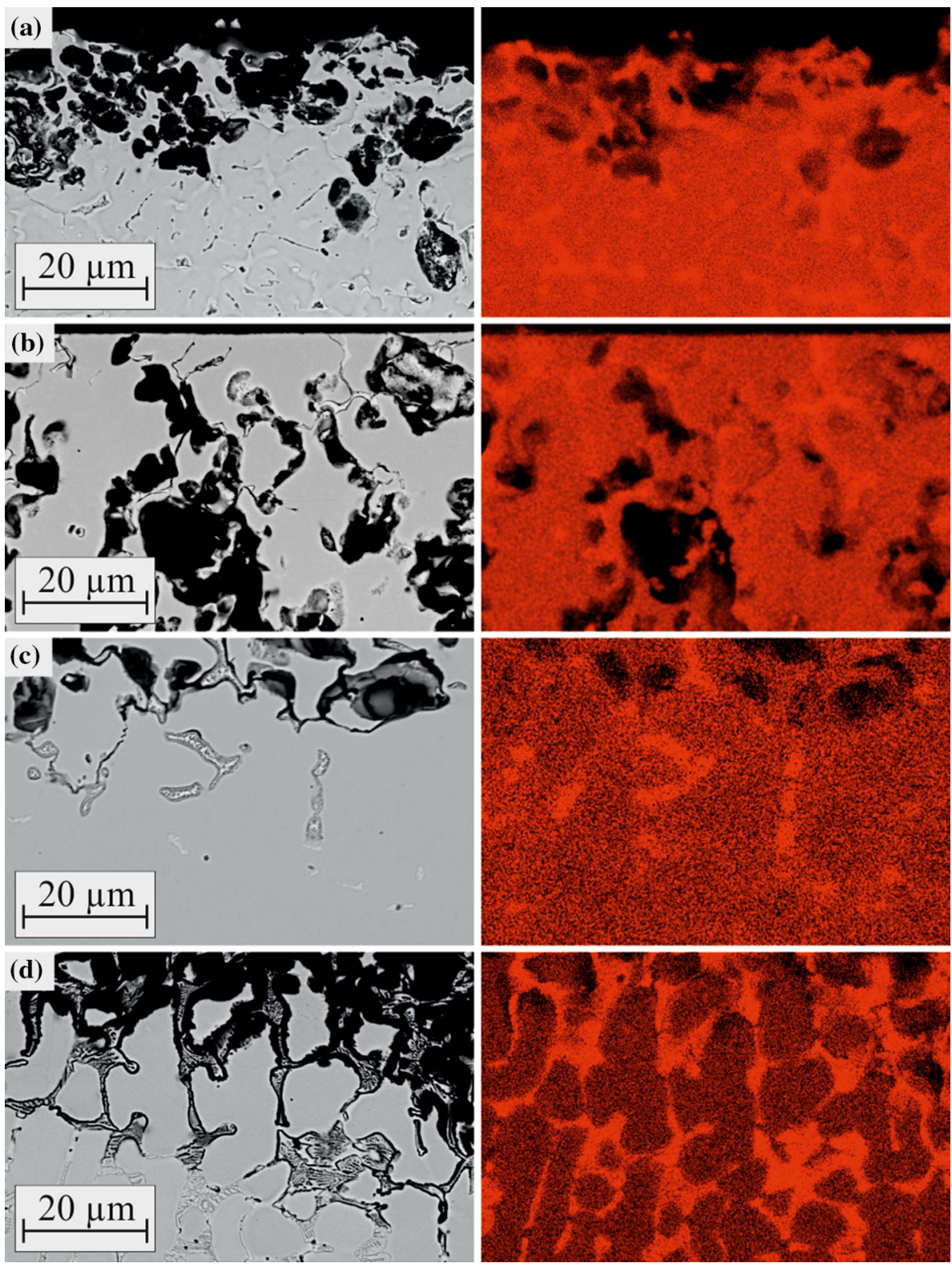

The heat distribution on the surface plays an important role on the microstructure. In GMA-SW, it is mostly influenced by the thermal conductivity of the shielding gas, which was increased by addition of helium. During the welding of the surface layers (by welding one bead next to the other), an increase in thermal conductivity of the shielding gas leads to a wider heat-affected zone. On the substrate side, a larger part of the base material melts and fuses with the weld metal leading to a higher dilution. On the surface layer side, larger parts of previously welded beads melt again or are at least exposed to a higher additional heat input. The investigations have shown that this affects the microstructure and, eventually, the resulting corrosion properties more than preheating does. With pure helium (highest heat conductivity), a distinct and interconnected network of carbides with very high chromium content permeates the surface layer. The described effect of chromium enrichment (and depletion) is much stronger if the thermal conductivity of the shielding gas is increased. Finally, the deterioration of corrosion properties is more pronounced. These mechanisms were even confirmed by PTA-SW at $400{ }^{\circ} \mathrm{C}$ preheating: The resulting surface layer had a dilution of $22.6 \%$, which is more than that of the GMA-SW surface layer welded at the same preheating temperature, but with argon-helium shielding gas that had a dilution of $19.7 \%$. However, the columnar arc in PTA-SW heat-affects a thinner area on the surface compared to the cone-shaped arc in GMA-SW, whose heat is even more distributed by the increased heat conductivity of the shielding gas that also comprises helium. Though 
both processes lead to a microstructure with carbides in an austenite matrix, the carbides in the microstructure of the PTA-SW surface layer did not grow as large as they could interconnect with each other. Eventually, this manifests in a small, yet actual, passive region in the potentiodynamic polarization test.

\section{Summary}

Surface welding of duplex stainless steel on gray cast iron was performed to improve the corrosion properties using GMA-SW and PTA-SW. Preheating and the thermal conductivity of the shielding gas affect the dilution of the surface layer with gray cast iron. Shielding gas and the shape of the arc, who determine the heat-affected area on the surface during welding, were found to have the major influences on the microstructure.

Analyses of potentiodynamic polarization measurements evidenced that all surface layers performed better than gray cast iron in artificial seawater. The corrosion behavior of the surface layer with lowest dilution, prepared with PTA-SW, can even be considered as good as a commercially available duplex stainless steel. The phase boundary between austenite and chromium-rich precipitates (carbides) is highly susceptible to corrosion. Under electrochemical impedance spectroscopy after $24 \mathrm{~h}$ immersion, various degrees of pitting corrosion happened on the surfaces. The surface layers with dilution of $10.5 \%$ and lower, which showed a passive region during polarization measurements, remained passive; however, the passive region of the PTA-SW surface layer with $22.6 \%$ dilution did obviously not suffice to maintain a stable passive film during the test. Pitting corrosion on the surface layers with $12.8 \%$ and higher dilution preferentially started at the transition between two weld beads. In this investigation, a dilution of $10.5 \%$ represented a limit for corrosion protection under immersion as well as-to some degreeunder external polarization in artificial seawater.

Further investigations will aim to more closely investigate the corrosion mechanism, e.g., using localized electrochemistry at the cross sections of low diluted surface layers. This will allow for investigation of areas more close to the base metal, where diffusion of, e.g., carbon into the surface layer also influenced the microstructure and the chemistry on a microscale.

Acknowledgments Open Access funding provided by Projekt DEAL. The authors wish to express their gratitude for the support of this work by the German research foundation DFG (Reference Number 289947989) and "Becas Chile" scholarship by the National Commission for Scientific and Technological Research (CONICYT).
Open Access This article is licensed under a Creative Commons Attribution 4.0 International License, which permits use, sharing, adaptation, distribution and reproduction in any medium or format, as long as you give appropriate credit to the original author(s) and the source, provide a link to the Creative Commons licence, and indicate if changes were made. The images or other third party material in this article are included in the article's Creative Commons licence, unless indicated otherwise in a credit line to the material. If material is not included in the article's Creative Commons licence and your intended use is not permitted by statutory regulation or exceeds the permitted use, you will need to obtain permission directly from the copyright holder. To view a copy of this licence, visit http://creativecommons. org/licenses/by/4.0/.

\section{References}

1. H. Tischner, Korrosionserscheinungen in Strömenden Medien Am Beispiel Von Chemiepumpen, Chem. Ing. Tec., 1989, 61(3), p 220-228

2. P. Meuter, Protecting Pumps Against Abrasive Wear, Sulzer Tech. Rev., 2001, 1, p 22-25

3. P. Dupont and M. Cugal, Expertenwissen Verbessert Produkte, Sulzer Tech. Rev., 2006, 88(2), p 22-25

4. D.R. Askeland, Materialwissenschaften: Grundlagen, Übungen, Lösungen, Springer, New York, 1996

5. Werner Gauggel and Bryan Johnson, Qualität Der Oberfläche, Sulzer Tech. Rev., 2007, 4, p 12-15

6. P. Dupont and J.-P. Peri, Pumpen Der Spitzenklasse, Sulzer Tech. Rev., 2011, 93(3), p 12-15

7. O. Durst, J. Ellermeier, T. Troßmann, and C. Berger, ErosionsKorrosions-Untersuchungen an Gradierten MultilayerChromkarbidschichten, Materialwiss. Werkstofftech., 2009, 40(10), $\mathrm{p}$ 756-768

8. U. Depner, J. Ellermeier, T. Troßmann, C. Berger, and M. Oechsner, The Effect of Layer Structure on Corrosion and Erosion Resistance of Thin Pvd Multilayer Films, Int. J. Mat. Res., 2011, 102(8), p 1014-1020

9. K. Bobzin, L. Zhao, M. Öte, T. Königstein, M. Oechsner, M. Siebers, G. Andersohn, and J. Ellermeier, Entwicklung Einer Neuartigen Wirtschaftlichen, Eisenbasierten Beschichtung Zur Erhöhung Der Lebensdauer Von Gussbauteilen Unter Dem Gesichtspunkt Der Korrosionsbeständigkeit, Materialwiss. Werkstofftech., 2017, 48(9), p 922-935

10. A. Gallego, J.F. Gil, E. Castro, and R. Piotrkowski, Identification of Coating Damage Processes in Corroded Galvanized Steel By Acoustic Emission Wavelet Analysis, Surf. Coat. Technol., 2007, 201(8), p 4743-4756

11. B. Heider, M. Oechsner, T. Engler, J. Ellermeier, U. Reisgen, R. Sharma, E. Zokoll, and E. Gonzalez, Influence of Carbon Diffusion on Microstructure and Wear Behaviour of Duplex Stainless Steel Surface Layers on Lamellar Grey Cast Iron, Materialwiss. Werkstofftech., 2019, 50(10), p 1165-1180

12. TMR Stainless, Pittsburgh, PA (USA), Verarbeitung Nichtrostender Duplexstähle-Ein Praktischer Leitfaden, 1st ed., (International Molybdenum Association, 2011).

13. I. Mitelea, I.-D. Utu, S.D. Urlan, and C.M. Crăciunescu, The Effect of the Solution Treatment Onto the Microstructure and Mechanical Properties of Mag Pulsed Welded Joints from X2crnimon22-5-3 Duplex Stainless Steels, Materialwiss. Werkstofftech., 2017, 48(11), p 1040-1048

14. M. Oechsner, G. Andersohn, J. Ellermeier, B. Heider, U. Reisgen, R. Sharma, S. Wieland, and E. Gonzales Olivares, Improvement 
of Corrosion Resistance of Gray Cast Iron Components By Surfacing With Gas Metal Arc Welding, in International Thermal Spray Conference (A.S.M. International, Ed., Orlando, FL, 2018), pp 647-654.

15. U. Reisgen, M. Oechsner, R. Sharma, J. Ellermeier, G. Andersohn, E. Zokoll, B. Heider, and E. Gonzales Olivares, Surface Layer of Duplex Steel on Lamellar Grey Cast Iron By Means of Metal Inert Gas and Plasma Transferred Arc Powder Welding Processes. J. Thermal Spray Technol. (in press).

16. U. Reisgen, K. Willms, S. Wieland, E. Gonzales, M. Oechsner, G. Andersohn, J. Ellermeier, and B. Heider, Process Control Strategy of Low-Energy Metal Inert Gas Welding and PlasmaArc Powder Surfacing For the Cladding of Duplex Steel on Cast Iron, in International Thermal Spray Conference (A.S.M. International, Ed., Orlando, FL, 2018).

17. U. Reisgen, K. Willms, S. Wieland, E. Gonzales, M. Oechsner, J. Ellermeier, M. Siebers, and B. Heider, Improving the Resistance of Grey Cast Iron Components By Cladding With Duplex Stainless Steel Using Controlled Gas Metal Arc Welding: Influence of Dilution on Corrosion Properties, Materialwiss. Werkstofftech., 2018, 49(12), p 1520-1537

18. C. Evci, H. Iş1k, and M. Macar, Effect of Welding Wire and Groove Angle on Mechanical Properties of High Strength Steel Welded Joints, Materialwiss. Werkstofftech., 2017, 48(9), p 912921

19. S. Selvi, A. Vishvaksenan, and E. Rajasekar, Cold Metal Transfer (Cmt) Technology_An Overview, Def. Technol., 2018, 14(1), p 28-44

20. Fronius International $\mathrm{GmbH}$, Schweißpraxis Aktuell: CmtTechnologie: Cold Metal Transfer-ein neuer MetallschutzgasSchweißprozess (WEKA-Media, 2013).

21. Z.H. Rao, J. Hu, S.M. Liao, and H.L. Tsai, Modeling of the Transport Phenomena in Gmaw Using Argon-Helium Mixtures. Part I-The Arc, Int. J. Heat Mass Transf., 2010, 53(25-26), p 5707-5721

22. K.H. Lo, C.H. Shek, and J.K.L. Lai, Recent Developments in Stainless Steels, Materials Science and Engineering: R: Reports, 2009, 65(4-6), p 39-104
23. E. Folkhard and G. Rabensteiner, Welding Metallurgy of Stainless Steels, Springer, New York, 1988

24. F. Brückner, D. Lepski, and E. Beyer, Modeling the Influence of Process Parameters and Additional Heat Sources on Residual Stresses in Laser Cladding, J. Therm. Spray Tech., 2007, 16(3), p 355-373

25. Z.H. Rao, J. Hu, S.M. Liao, and H.L. Tsai, Modeling of the Transport Phenomena in Gmaw Using Argon-Helium Mixtures. Part II-The Metal, Int. J. Heat Mass Transf., 2010, 53(25-26), p 5722-5732

26. Voestalpine Böhler Welding GmbH, "Thermanit 22/09: Massivdraht, hochlegiert, rostfrei”, 2014.

27. Castolin Eutectic, "EuTroLoy 16462: Metallpulver für korrosionsbeständige Beschichtungen", 2014.

28. J. Ellermeier, Metallurgisch-technologische Untersuchungen von Hartlegierungen für das Plasma-Pulver-Auftragschweißverfahren, Dissertation, RWTH Aachen, 1996.

29. U. Dilthey, J. Ellermeier, and A.V. Pavlenko, Spektralsensor Zu "Online"-Aufmischungsbestimmung Beim Schweißtechnischen Beschichten, Schweißen und Schneiden, 1996, 47(3), p 227-230

30. W.H. Mulder, J.H. Sluyters, T. Pajkossy, and L. Nyikos, Tafel Current at Fractal Electrodes: Connection With Admittance Spectra, J. Electroanal. Chem., 1990, 285, p 103-115

31. A.L. Schaeffler, Constitution Diagram For Stainless Steel Weld Metal, Met. Prog., 1949, 56(5), p 680

32. D.M.E. Villanueva, F.C.P. Junior, R.L. Plaut, and A.F. Padilha, Comparative Study on Sigma Phase Precipitation of Three Types of Stainless Steels: Austenitic, Superferritic and Duplex, Mater. Sci. Technol., 2013, 22(9), p 1098-1104

33. A. Karl, Laserauftragschweißen hochlegierter Duplex-Stähle, Dissertation, Technische Universität Ilmenau, 2013.

34. T. Wegrzyn, Delta Ferrite in Stainless Steel Weld Metals, Weld. Int., 1992, 6(9), p 690-694

35. H. Boehni, Breakdown of Passivity and Localized Corrosion Processes, Langmuir, 1987, 3(6), p 924-930

Publisher's Note Springer Nature remains neutral with regard to jurisdictional claims in published maps and institutional affiliations. 